\title{
A review of solvent action on oil paint
}

\author{
Lambert Baij ${ }^{1} 2^{*} \mathbb{D}$, Joen Hermans ${ }^{1,2}$, Bronwyn Ormsby $^{3}$, Petria Noble ${ }^{2}$, Piet ledema ${ }^{1}$ and Katrien Keune ${ }^{1,2}$
}

\begin{abstract}
The science of oil paint cleaning is an interdisciplinary and challenging field of study due to the complex nature of both paintings and cleaning materials. The topic requires an intimate and iterative collaboration between conservation scientists and paintings conservators. In such an interdisciplinary field, it can sometimes be difficult to interpret the practical applicability of the available literature. This review aims to bring both conservators and scientist up-todate on the recent advances in the literature on oil paint cleaning and proposes a framework for experimental and theoretical investigations into solvent transport in oil paint. We define the physicochemical processes that occur simultaneously during cleaning as solvent action and investigate how these processes vary with the polymeric structure of the oil binding medium. The sections in this overview of the technical cleaning literature are divided into solubility, swelling and diffusion, leaching, solvent evaporation and retention and solvent-mediated chemical reactions. Models that have been used to predict varnish solubility or oil paint swelling, such as Teas chart, are critically reviewed from the perspective of the most recent developments in the various scientific disciplines involved. Technological developments in the field of modern materials for solvent- and water-based cleaning are also discussed. Finally, an outlook for the field of cleaning science is presented.
\end{abstract}

Keywords: Oil paint, Solvent action, Cleaning

\section{Introduction}

The French philosopher Étienne Gilson once said: 'There are two ways for a painting to perish, the one is for it to be restored; the other is for it not to be restored' [1]. In order to resolve this dilemma, a paintings conservator ideally knows as much as possible about how the paint material can be adversely affected by cleaning.

Paintings conservators go through great efforts to enhance the readability and appearance of paintings. For that purpose, cleaning actions like the removal of old or discoloured varnish layers or other unwanted conservation materials may be required. For varnish removal, cotton swabs with organic solvents such as acetone, ethanol and hexanes are commonly used, whereas aqueous solutions with additives are mostly used to remove surface dirt. The growing corpus of scientific literature dealing with the physicochemical aspects of oil paint alterations

\footnotetext{
*Correspondence: c.l.m.baij@uva.nl

${ }^{1}$ Van 't Hoff Institute for Molecular Science, University of Amsterdam, Science Park 904, PO Box 94157, 1090GD Amsterdam, The Netherlands Full list of author information is available at the end of the article
}

has shed new light on the possible unwanted side-effects of solvent-based cleaning [2-6]. In this review, we will discuss the known physicochemical processes that can be induced or enhanced by solvent exposure, and how these processes may be influenced by the properties of the paint material.

Although conservators and conservation scientists now universally recognise that the majority of paintings is affected by diverse and widespread alteration phenomena, these phenomena remain poorly understood. As a result, paintings conservators routinely treat objects without a full understanding of the chemical processes and material properties of the paint. Examples of important paint alteration phenomena include cracking of the paint, the discoloration of pigments, the yellowing of varnishes, dirt accumulation, the formation of protrusions and crystalline material deposits on the surface and increased transparency of paint layers $[7,8]$. The observation of these slow chemical alterations has resulted in the realisation that paintings can no longer be seen as static objects. For example, factors such as relative humidity (RH)

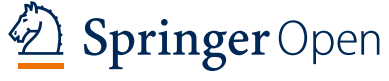

(c) The Author(s) 2020. This article is licensed under a Creative Commons Attribution 4.0 International License, which permits use, sharing. adaptation, distribution and reproduction in any medium or format, as long as you give appropriate credit to the original author(s) and the source, provide a link to the Creative Commons licence, and indicate if changes were made. The images or other third party material in this article are included in the article's Creative Commons licence, unless indicated otherwise in a credit line to the material. If material is not included in the article's Creative Commons licence and your intended use is not permitted by statutory regulation or exceeds the permitted use, you will need to obtain permission directly from the copyright holder. To view a copy of this licence, visit http://creativeco mmons.org/licenses/by/4.0/. The Creative Commons Public Domain Dedication waiver (http://creativecommons.org/publicdomain/ zero/1.0/) applies to the data made available in this article, unless otherwise stated in a credit line to the data. 

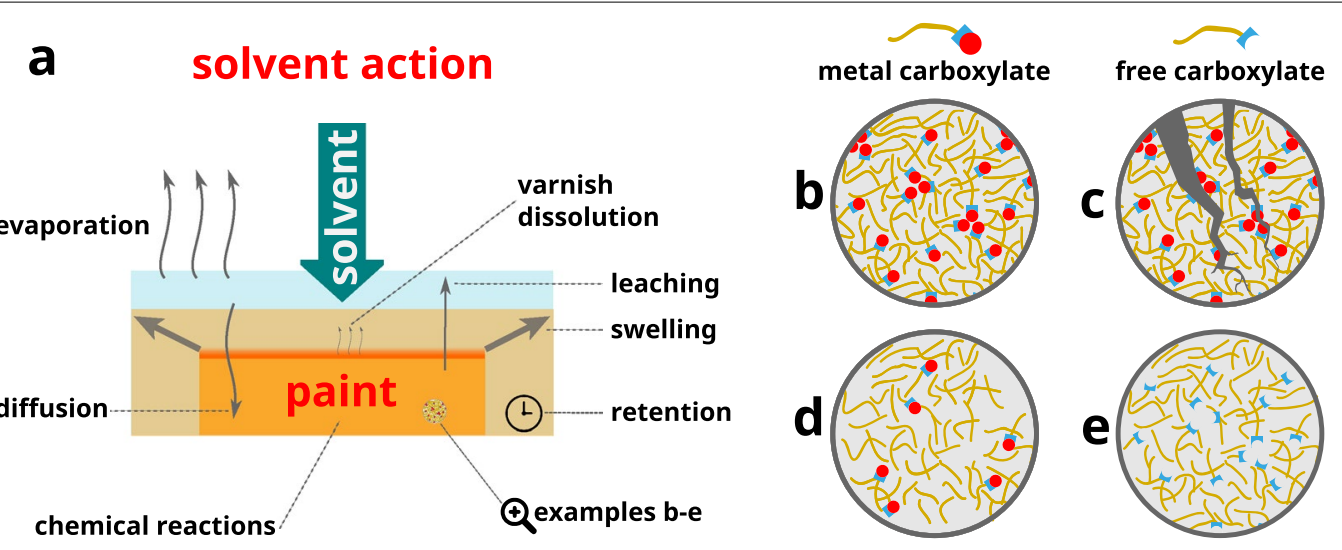

Fig. 1 a Schematic indication of physicochemical processes that occur simultaneously during cleaning operations, altogether defined as solvent action. After and during the dissolution of varnish (orange), the paint matrix (yellow) expands in size (shaded yellow) due to the uptake of solvent (blue). The relative thickness of the layers indicated does not represent the actual thickness. $\mathbf{b}-\mathbf{e}$ Schematic examples of possible structure in the polymeric binding medium in oil paint. b Aged ionomeric binding medium with metal carboxylates and high degree of cross-linking, $\mathbf{c}$ cracked ionomeric binding medium with metal carboxylates and high degree of cross-linking (shown crack diameters are not to scale), $\mathbf{d}$ ionomeric binding medium with metal carboxylates and low degree of cross-linking, e highly oxidised binding medium with intermediate degree of cross-linking and a high concentration of free carboxylic acid groups

$[9,10]$, solvent exposure [11-13], fluctuations in temperature [14] and exposure to light [15-18] have been shown to enhance the alteration and degradation of oil paints. Many of these oil paint alteration processes are the result of pigment-binder reactions that lead to a change in the chemical structure of oil paintings, which can affect the stability and appearance of whole works of art. Solvent-swelling in particular can enhance the mobility of reactive paint components, which poses the risk of accelerating certain degradation phenomena [13]. However, although a considerable amount of progress has been made [5, 6, 19-21], the knowledge of the influence of solvent-based cleaning on fundamental chemical and physical processes remains limited and does not currently allow for a reliable estimation of the risks involved in cleaning. This lack of comprehensive risk estimation procedures that depend on measurable paint or solvent properties, has led to the consensus that solvent exposure on paintings should be minimised altogether.

In order to assess the risks associated with solvent exposure, one should have extensive knowledge of the chemical and physical processes occurring in paint layers and know how these processes can be influenced by solvent exposure. Because most paintings necessarily undergo cleaning treatments, it is of vital importance for the conservation of works of art to advance our understanding of solvent action on oil paint and work towards a reliable assessment of the risks involved in solvent-based cleaning.

\section{Physicochemical processes relevant for cleaning}

For an accurate and complete description of the processes involved in solvent cleaning the following processes need to be considered: varnish dissolution, paint swelling, solvent diffusion,--evaporation,-leaching and chemical reactions inside paint (Fig. 1a). In this review, we define the total combined physicochemical influence of these processes (Fig. 1a) as solvent action. Therefore, solvent action can be viewed as a collective term describing the rate of solvent transport processes inside the paint, including chemical reactivity induced by the uptake of solvents. Solubility is well described by equilibrium thermodynamics ("Theoretical prediction of solubility" section). Swelling of paint, a tangible phenomenon for a conservator, has two distinct aspects: equilibrium swelling and swelling kinetics. Equilibrium swelling is partly governed by thermodynamics, but needs additional parameters concerning polymer properties. Swelling kinetics involves mass (e.g. solvent) transport in the paint film, which places this process in the well-developed and vast scientific area of diffusion of low-molecular weight substances in polymers. Equilibrium and kinetic effects require a separate theoretical description, but the distinction between the two is often overlooked in art cleaning studies. A higher degree of complexity is faced when also considering evaporation of solvent in relation to its retention time in a paint film. Simultaneous description of evaporation and retention is a complex interplay of processes, since the rate of swelling and deswelling may be limited by the rates of either evaporation from the surface or diffusion inside the film. Similarly 
complex processes are encountered in leaching, where soluble extractables (non-crosslinked oil components and oxidation products) diffuse outwards towards the surface, while solvent diffuses inwards into the bulk of the paint. The simultaneous transport of multiple species inside polymers is called multicomponent diffusion and either one of these diffusion rates may be rate-determining. The ultimate complexity occurs when all aforementioned processes occur together with chemical reactions invoked by reactive groups present in partially degraded paint films. Solvent-induced reactivity in paints has only recently been identified as a crucial and potentially artworks endangering issue [13].

All the aforementioned processes deserve a separate theoretical description, which defines the textual structure of this review paper: in order of increasing complexity. Nevertheless, it should be emphasised that in cleaning practice the different processes occur simultaneously. The extent to which any of these processes (Fig. 1a) occur, depends on the amount of solvent that is applied (varying with application method) and the rate of solvent transport inside the paint. The rate of solvent transport inside the paint depends on the condition of the paint and is influenced by factors such as the presence of (micro) cracks or soluble extractable materials. It should also be recognised that these transport processes are generally interconnected. For example, faster diffusion will result in faster swelling [22] and possibly in faster leaching and evaporation. Solvent-induced chemical reactions, such as zinc soap formation (discussed in "Solvent-mediated reactivity" section), are happening at the same time as dissolution, diffusion and evaporation. For the conservator, the swelling of paint (possibly resulting in softening of the paint and pigment pickup), is the most easily detected phenomenon in the list of processes mentioned above (Fig. 1a). Although the change of gloss is sometimes attributed to leaching, it may also be due to re-deposition of varnish residues after cleaning or due to the increased visibility of the porosity of the paint that leads to blanching [23]. Because the diffusion of water in intact oil paints is very slow [22] and the solubility of most paint components in water low, solvent diffusionswelling and-leaching apply to a much lesser extent to aqueous cleaning.

The fact that no (analytical) techniques exist that can measure solvent action (Fig. 1a) under realistic treatment conditions has seriously hampered quantitative studies on the influence of cleaning on oil paints. Moreover, some concessions generally need to be made by conservation scientists in the design of simulated cleaning treatment experiments. For example, an important factor in cleaning research is the choice between using model systems and real paintings for experiments. This decision may depend on the analytical methods and sample size, among other things, and is intimately related to the challenge of balancing the theoretical relevance (e.g. reproducibility) of the cleaning experiment and the practical relevance of the cleaning treatment. For example, the use of long immersion times for leaching studies may yield highly accurate data on extractables, but the results may be less easily translated into conservation strategies because of the short contact times encountered in cleaning practice. Finding the optimal balance between theoretical and practical relevance of cleaning experiments has led to many discussions [24-27]. We will attempt to highlight the practical relevance of the literature discussed throughout this review.

\section{A chemical view on oil paint}

Solvent action (Fig. 1a) depends strongly on the chemical and physical properties of the materials that will be exposed to solvents. To understand the origins of these material properties, a chemical view on oil paint can be taken. A chemical view on traditional and modern oil paint regards the paint material as a mixture of complex metal salts or conjugated organic dyes (inorganic or organic pigments), a polymerised, triglyceride-based drying oil, and often a variety of additives. A painting is thus a metastable, multilayered, heterogeneous polymeric material. The material composition, stratigraphy of the paint layers with their respective chemical differences and state of degradation, constitute this complex polymeric material. Although a painting can be considered metastable as a whole, certain layers may locally respond differently to solvent exposure than others, resulting in disturbance of local chemical equilibrium due to the displacement or removal of non-crosslinked oil components. Consequently, understanding autoxidation of the oil [28-30], the degradation of pigments [15-18, 31], pigment-binder interactions [32], the chemistry of varnishes [5,33] and their degradation [34-37] and the composition of dirt $[38,39]$ are a prerequisite to understand the influence of solvent action. All these factors are relevant when choosing the method to treat a paint surface, which depends on the chemical composition of the materials and their respective state of degradation.

\section{Oil paint cleaning is polymer chemistry}

Despite the overwhelming complexity of both paint materials and degradation phenomena, solvent action always concerns the transport and interaction of solvents within the polymeric binding medium. Therefore, in order to understand the influence of cleaning on oil paint, it is crucial to view oil paints as pigment-filled polymers and focus on the properties of the polymeric structure of the binding medium (Fig. 1b-d). Because 
solvents diffuse and interact with these polymers, polymer properties such as degree of cross-linking, polarity, concentration of plasticisers and ion-content determine the sensitivity towards solvents. If the properties of the polymer change, the sensitivity for solvents changes. The properties of these drying oil-based polymers are determined by the chemical composition and the environmental conditions during the lifetime of a painting. The wide range of paint materials and environmental conditions results in diverse polymeric structures (see Fig. 1b-d for examples), which determine to what extent solvent action (Fig. 1a) can occur during cleaning treatments.

The polymer chemistry literature provides an abundance of relevant information for cleaning studies. An important example is that oil paint binding media in paintings where zinc or lead-based pigments are present, feature strong similarities with a class of metal-ion-containing polymers called ionomers [40, 41]. Ionomers were recently identified as representative models for mature oil paint binding media [40, 41]. However, they have been widely studied for applications in packaging, adhesives, fuel cell membranes [42, 43], bio-mimetic sensors [44, 45], water purification [46] and drug delivery [47]. The network structure in oil paint ionomers is more complex than in most industrial ionomers due to the complexity of the triglyceride monomer itself and the complex autoxidation pathways responsible for network formation. Nevertheless, the available literature concerning transport of water and organic solvents in (ion-containing) polymers and alkyd resins [48-54] provides a useful starting point for oil paint cleaning studies. Relevant examples include methodologies for measuring or modelling dynamic processes in polymers, such as solvent swelling and (multicomponent) diffusion, ion-transport [55-62] and plasticiser-effects (such as added fatty acids or metal soap complexes [63-65]). Vice versa, oil paint research can also stimulate and advance the use of uncommon analytical techniques such as two-dimensional infrared (2D-IR) spectroscopy [41] or In-Air Plasma-Induced Luminescence (In-Air-PIL) spectroscopy in material science [66]. Considering the recently renewed interest in bio-based alkyd paints [67, 68], efforts towards understanding oil paint chemistry are certainly relevant in the broader perspective of industrial applications and polymer science. Currently, the collaboration between polymer science and cleaning studies remains limited, but research initiatives that contribute to bridging this gap were recently presented [69]. In this review, several examples of how polymer research can advance the understanding of solvent transport in oil paint are given (see for example "Swelling of paint by solvents", "Solvent-mediated reactivity" and "Modern materials for cleaning" sections).

\section{Polymer structure and solvent sensitivity}

In conservation science, the wide range of properties of the polymeric binding medium is not always recognised. Instead, polymer structure is often discussed in terms of differences in solvent sensitivity. Solvent or water sensitivity occurs in cases where the binding medium has such a low degree of polymerisation and high degree of oxidation (due to network degradation or inherently low cross-linking) that minor mechanical action removes pigment particles [70]. Water sensitivity is a special case of solvent sensitivity. When water sensitivity is reported, high concentrations of extractable free dicarboxylic acids are often found [71-73], together with a low degree of polymerisation of the binding medium [74]. Therefore, the wide variety of cases where solvents sensitivity is reported provide examples of how differences in the polymer properties of the binding medium influence solvent action. Because the majority of inorganic pigments are inert towards solvents or water, inorganic pigment properties generally only play an indirect role in solvent sensitivity due to their respective influence on the drying and ageing of the oil, resulting in differences in the polymeric structure of the binding medium. Besides the indirect influence of chemical pigment properties, the concentration of pigments also plays an important role in determining the final polymeric structure of the oil and therefore solvent sensitivity.

To discuss how pigment chemical properties and pigment concentration can influence the polymeric structure of the oil, a concept that originates from coatings literature named critical pigment volume concentration (CPVC) is recommended. CPVC is defined as the 'random tightest possible packing of pigment particles and the minimum amount of binder necessary to fill the interstices between particles' [75]. Although the concept of CPVC is often used in the conservation field to define a workable paint with good coverage, it is often overlooked that pigment concentration strongly influences the curing of the paint due to the influence of PVC on oxygen diffusion. As a result, the polymer properties of the binding medium are influenced by the PVC, which in turn will influence how solvents will interact with the polymerised oil medium. It is known that many coating properties change significantly at the CPVC [75]. Below the CPVC the coating film is continuous and made only of binder and pigments. Above the CPVC the film is discontinuous due to the presence of air pockets around pigment particles that replace the binder [75]. The curing of alkyd paints (which crosslink via a similar mechanism as oil paint) depends on the PVC: below the CPVC the drying rate is independent of degree of pigmentation and a reaction front due to oxygen diffusion is observed, directed from the top of the paint inwards. Above the 
CPVC, a coating cures more homogeneously due to the faster oxygen diffusion through voids between pigment particles [76].

It is widely recognised that metal ions released by inorganic pigments can influence the drying of oils [29, 30], which leads to vastly different properties in the resulting polymerised oil network. Examples of how pigment properties may influence the polymerisation of the binding medium, are paints based on ultramarine [77] or anatase titanium dioxide [78] pigments, which are known to enhance the breakdown of the binding medium and lead to the formation of powdery paints. Powdery paints can be considered to possess a PVC > CPVC, because only a small amount of binding medium remains intact. Notorious water sensitive paints include ultramarine blue $[6,77,79]$, cobalt blue [72] and cadmium and chrome yellow [71]. Certain synthetic organic pigments also have some inherent solubility in organic solvents [80], which is probably the only scenario where the structure of the polymeric binding medium is less important and solvent sensitivity will be mostly determined by the properties of the solvent.

In general, paints containing organic pigments are more sensitive to organic solvents [81], even though they often contain a PVC $<$ CPVC. An interesting case illustrating how PVC and pigment properties may influence the polymerisation of the oil and result in solvent sensitivity, are medium-rich organic blacks. Firstly, inhomogeneous and incomplete drying limited by oxygen diffusion (due to the low PVC) may result in a low degree of cross-linking and explain how carbon or bone black paints are solvent sensitive. Secondly, the absence of metal ions that enable ionic crosslinks (such as zinc or lead), causes organic blacks to lack metal carboxylate crosslinks. Thirdly, the absence of metal ions can influence the autoxidation of the binding medium, further reducing the degree of polymerisation and enhancing their solvent-sensitivity. Although it is currently unclear which of these hypotheses is most relevant, it is clear that the structure of the polymerised binding medium governs the degree of solvent sensitivity.

In summary, solvent sensitivity is intimately linked to the polymer properties of the binding medium, which is indirectly affected by pigment type and concentration because these factors can influence the cross-linking of the oil.

\section{Early cleaning studies}

With the theoretical framework defining solvent action in mind, we can now continue to investigate the technical literature on the cleaning of oil paint, starting with the early investigations and proceeding with separate treatments of the various processes involved.
Scientists have been studying the effects of cleaning on paintings for more than two hundred years. The importance of the chemistry of paint and varnishes was even recognised in the 18th century. Trained as an apothecary, Robert Dossie (1717-1777) provided detailed information about cleaning practice for painted surfaces in his Handmaid to the Arts (1758) [82]. He noted that: 'the art of cleaning pictures and paintings is of great consequence in preserving valuable works of that kind, but has been very little understood even by those who profess to practice it' [82]. In the 19th century, a number of important scientists were involved in studies of paint chemistry [83]. In the 1850s, Michael Faraday (1791-1867) investigated varnishes, cleaning methods and the impact of coal smoke and gas lighting on the discoloration of surface coatings for the National Gallery in London. In the 1870s, the chemist and biologist, Louis Pasteur (1822-1895) investigated the yellowing of varnishes at the Ecole des Beaux-Arts in Paris [5]. In Germany, Max von Pettenkofer (1818-1901), a Bavarian chemist, patented a process of exposing blanched paintings to alcohol vapour and copaiba balsam [5]. The Pettenkofer method was later found to have induced 'severe disruptions' of the paint and varnish layers and paintings were sometimes referred to as being 'Pettenkofered', highlighting the risks involved in cleaning paintings [5]. The role of chemists in conservation grew considerably in the 20th century when a scientific department was established at the Staatliche Museen in Berlin in 1888 and the British Museum in 1921 [83]. Professor of chemistry Sir Arthur H. Church published his comprehensive handbook 'The Chemistry of Paints and Paintings' in 1915 [84]. In the Netherlands, Martinus de Wild was probably the first to combine conservation and restoration with scientific training. In his dissertation (1928), de Wild provided an in-depth discussion on the chemistry of common traditional pigments and advice on the cleaning of paintings. For example, de Wild stated that it is 'best to completely remove an old varnish layer', that alcohol is an effective solvent for that purpose and that mixtures of solvents e.g. alcohol and xylene) can be used to 'decrease the rapid action of the alcohol' if required [85].

It was not until the 1950s however, that systematic scientific studies focusing on solvent action on oil paint films took a leap. The early cleaning studies by Stolow [86-88] have provided valuable insights for paintings conservation practice and are still major source for the evaluation of solvent action on oil paint today. However, the effects of cleaning on paintings have also continually been a topic of considerable controversy [26, 89, 90]. Besides the scarcity of technical literature, cultural and ethical aspects of cleaning make this a topic that is 
among 'the most contentious' of all the interventions works of art may undergo [90].

\section{Solubility, swelling and diffusion}

The solubility of (aged) varnishes, oil components and unwanted polymeric materials in organic solvents is an important topic in cleaning studies because it determines how easily these materials can be removed. Before starting actual cleaning, solubility tests are often conducted on small areas of the painting to assess the solubility of the materials and choose a proper solvent (mixture) and method of application. It would however be desirable to predict the solubility of these materials using a theoretical model because this would enable an easier selection of cleaning tools and reduce the need for solubility tests. Hence, it is not surprising that some theoretical solubility models were developed or adapted from other fields of study.

\section{Theoretical prediction of solubility The Hildebrand and Hansen models}

Solubility studies in art cleaning are mostly based on thermodynamics of dilute solutions. Thermodynamics of dilute solutions describe the equilibrium condition in solvent-solute (in our case mostly solvent-varnish) mixtures and therefore consider small amounts of solid materials to be dissolved and removed by cleaning solvents. However, the use of organic solvents on a painting hardly qualifies as a dilute solution, since a limited amount of solvent is used, the contact times are often short (which means solvent-solute equilibrium and equilibrium swelling may not be reached) and soluble paint components are encapsulated in a tightly crosslinked polymeric binding medium. Moreover, thermodynamics of dilute solutions do not account for energetic terms involved in the interaction of a solvent with the polymeric binding medium, which is often called non-ideal behaviour. Thermodynamic theories describes solventsolute equilibrium in terms of ideal mixing behaviour and deviations thereof. In the Flory-Huggins (FH) theory [91] such deviations are attributed to intermolecular interactions, expressed in terms of differences in molar volume and the FH interaction parameter. The use of FH theory to describe solubility is recommended and the interaction parameter is also used in the Flory-Rehner theory of polymer swelling, which is discussed in "Theoretical prediction of swelling" section. Currently, only very few examples of $\mathrm{FH}$ theory are presented for cleaning science [92].

In the 1950s, Hildebrand [93] also formulated a theory describing non-ideal solvent-solute behaviour, which is related to the FH interaction parameter. Hildebrand's approach formed the basis for the most widespread model aiming to predict varnish solubility and minimise paint swelling used by the conservation community [94]. The model is based on the Hildebrand total solubility parameter $\delta_{t}$ [93], which is defined as the square root of the cohesive energy density, a measure of the intermolecular interactions within a pure solvent. The solubility parameter $\delta_{t}$ is related to the heat of mixing of the two components (solvent and solute) and approaches a minimum if the Hildebrand solubility parameters of the solute and the solvent are close [95]. To account for interactions between more polar molecules and for hydrogen bonding, Hansen subsequently developed a model with three parameters [96, 97], later referred to as Hansen solubility parameters (HSP):

- $\delta_{d}$ dispersion forces

- $\delta_{p}$ dipolar intermolecular forces

- $\delta_{h}$ hydrogen bonds.

The HSPs add up to the Hildebrand total solubility parameter $\left(\delta_{t}\right)$ according to $\delta_{t}=\delta_{d}+\delta_{p}+\delta_{h}$ and can be treated as coordinates for a point in three dimensional space. The nearer two compounds are, the more likely they are to dissolve (often referred to as like-dissolveslike rule). To determine whether the parameters of two substances (usually a solvent and a polymer) are close, a value called interaction radius is given to the substance being dissolved. This value determines the radius of a sphere in Hansen space with the center defined by the HSPs. The HSPs formed the basis for the so called Teas chart [94], which is still used in cleaning science.

\section{The Teas chart}

In the Teas chart all three Hansen parameters are plotted on a single planar graph (Fig. 2). Teas parameters are fractions and are related to Hansen parameters through Eq. 1. Hence, Teas parameters express the relative contribution (multiplied by 100 to obtain a percentage) of each Hansen parameter to the total Hildebrand value:

$$
\begin{aligned}
f_{d} & =\frac{\delta_{d}}{\delta_{d}+\delta_{p}+\delta_{h}}, \quad f_{p}=\frac{\delta_{p}}{\delta_{d}+\delta_{p}+\delta_{h}}, \\
f_{h} & =\frac{\delta_{h}}{\delta_{d}+\delta_{p}+\delta_{h}}
\end{aligned}
$$

The construction of the Teas chart is based on the assumption that all materials have the same Hildebrand total solubility value $\left(\delta_{t}\right)$. According to this assumption, solubility behaviour is determined by the relative magnitude of the three molecular forces $\left(\delta_{d}, \delta_{p}, \delta_{h}\right)$ that contribute to the total Hildebrand value $\delta_{t}$. However, since $\delta_{t}$ is not even approximately constant for different polymers 


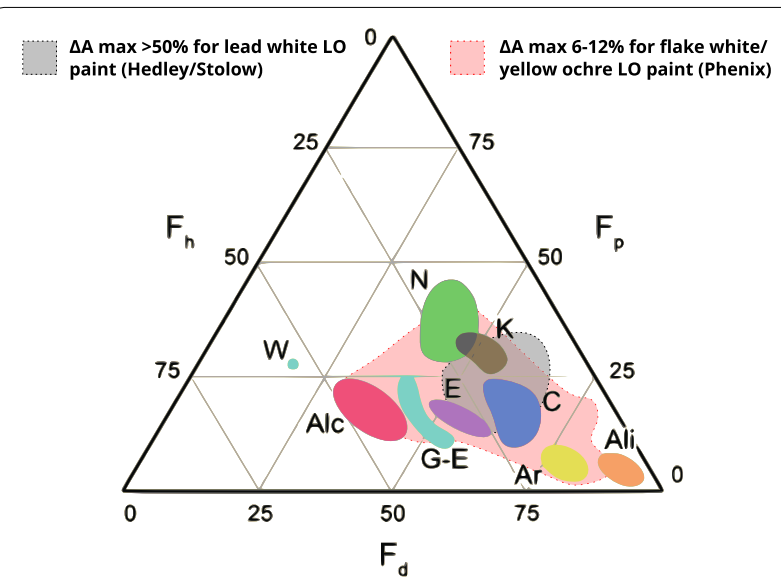

Fig. 2 The Teas chart, projecting three dimensional Hansen solubility parameters onto a triangular space. 'Peak swelling' region identified by Hedley [98] based on data from Stolow (see "Theoretical prediction of swelling" section) in grey, extended 'peak swelling' region based on different paint types identified by Phenix in light red. $W=$ water, $\mathrm{N}=$ nitrogen containing solvents, $\mathrm{K}=$ ketones, $\mathrm{Alc}=$ alcohols, $\mathrm{G}-\mathrm{E}$ $=$ glycol ethers and esters, $\mathrm{E}=$ esters, $\mathrm{C}=$ chlorinated solvents, $\mathrm{Ar}$ $=$ aromatics, Ali $=$ aliphatics. Image adapted from Chelazzi et al. [99] and Phenix [100]

[101], this approach leads to the loss of $\delta_{t}$ as independent parameter. For varnishes and drying-oil based polymers as the solute species, this seems to be a bad assumption and can lead to significant inaccuracy in the fractional Teas parameters [101, 102].

It should be emphasised that projecting three HSPs onto a triangular chart inevitably leads to the loss of information. As early as 1989, Stavroudis [103] warned the conservation field about the severe limitations of the Teas chart (the titles were 'No Teas-ing' and 'Teas-Busters') and proposed to ban it. It was realised that, using the triangular Teas chart, the 'range of solubilities of a polymer is distorted' and 'relations between solvents are lost' [103]. This issue was also put forward by Phenix, noting that solvents with clearly different solubility properties are clustered close together in the chart [100] (e.g. ketones and nitrogen containing solvents in Fig. 2). In the Teas chart, most solvents fall within a narrow region of solubility parameters.

\section{Other classification models}

The relative inaccuracy of both Hildebrand and Hansenbased models (which includes the Teas chart) was recently illustrated in the review by Brouwer and Schuur. The prediction of activity coefficients at infinite dilution $\left(\gamma_{i}^{\infty}\right.$, often used to characterise solvent-solute interactions) was compared for a range of models [91]. The Hildebrand parameter features the largest error with an average relative deviation (ARD) of $>10^{5} \%$ in the $\gamma_{i}^{\infty}$ prediction. Using the HSP to calculate the $\gamma_{i}^{\infty}$ with significant improvement, compared to the Hildebrand model but still, an ARD of $66.4 \% \pm 14.4 \%$ is observed for solvents [91]. More recently, models like COSMO-RS, the Abraham model and MOSCED have been developed that perform much better [91]. The use of these models to predict solvent interactions with a range of materials used in conservation and restoration is recommended.

Phenix and Graczyk recently proposed the use of solvatochromic polarity as an indicator of solvent properties [104, 105]. This methods ranks solvents according to normalised Reichardt solvatochromic polarity $\left(\mathrm{E}_{T}^{N}\right)$ and refractive index $(n) . \mathrm{E}_{T}^{N}$ values are polarity values based on the colour changes of pyridinium- $\mathrm{N}$-phenoxide betaine in a solvent and are referenced to the polarity of tetramethylsilane (TMS, apolar) and water (polar) [106]. The advantages of this model are that it provides an empirical description of the polarity of solvents and that $\mathrm{E}_{T}^{N}$ and $n$ can readily be determined for unknown solvents or solvent mixtures. Concerning mixtures of solvents, significant deviations from linearity are observed in the relationship between $\mathrm{E}_{T}^{N}$ and $n$ [105]. Although plotting $\mathrm{E}_{T}^{N}$ versus $n$ does show increased clustering within classes of solvents [105] as compared to Teas or Hansen solubility parameters, the classifications of a wider range of solvents remains challenging.

In an attempt to do justice to the short contact times encountered in cleaning practice, a method that claims to take the dissolution rate of varnishes into account was developed by Zumbühl [107]. The dissolution rate of a range of varnishes was studied and found to strongly accelerate at vapour pressures exceeding $100 \mathrm{hPa}\left(25^{\circ} \mathrm{C}\right)$. The correlation between rate of dissolution and vapour pressure was also confirmed for the leaching of paints materials at short immersion times. Most importantly, it was found that the rate of dissolution after short solvent exposure is not influenced by the potential swelling capacity at longer timescales [107]. This study illustrates well the confusion that is created when attempting to explain kinetics (of dissolution) from purely thermodynamic equilibrium considerations (vapour pressure).

\section{Swelling of paint by solvents}

Solvent swelling is a tangible phenomenon because the mechanical and optical properties of the paint surface can change due to the swelling process. During the removal of old varnishes, swelling will result in an altered 'feel' of physical interaction with the paint surface during swabbing. Because of the expansion of the oil matrix by solvent ingress, swelling may result in pigment loss [71], which prompts the conservator to change solvent, application method or halt the cleaning action. 


\section{Theoretical prediction of swelling}

Most early literature on the cleaning of oil paint focused on the swelling- and de-swelling behaviour of relatively young oil paints films in organic solvents. Pioneering studies into solvent swelling were carried out by Stolow in the 1950s [86-88]. An important objective of this research was the prediction of paint swelling from solvent properties.

It is surprising that the solubility model by Hansen $[96,97]$ and the simplified version by Teas [94] were subsequently also used by the conservation community to predict swelling [100] since these models were originally intended to describe dilute solutions of a polymer in a solvent. Solvent volume fractions during the swelling from dry polymer (no solvent) to equilibrium swollen polymer are much lower than in dilute solutions. Yet, describing swelling of oil paint using dilute solution theory has, despite the existence of theories specifically dedicated to polymer swelling such as Flory-Rehner, been a long tradition in cleaning science [94, 100, 108, 109]. Consequently, it is not surprising that Zumbühl, having investigated 37 solvents and 75 solvent mixtures, came to the conclusion that no quantitative or qualitative prediction of solvent swelling was possible with the Teas chart [108]. Stolow ranked the swelling capacity of solvents in oil paint and formulated a 'peak-swelling region' that was later plotted onto the Teas chart (Fig. 2) [98]. This approach was taken in order to minimise paint swelling and enable the conservator to choose solvent (mixtures) outside the peak-swelling region [98]. However, the equilibrium swelling region for oil paint (grey area in Fig. 2) as identified by Hedley [98] using data from Stolow [87], can shift depending of the paint type and age [110], rendering the use of the Teas chart to predict swelling problematic. Figure 2 shows that the region for equilibrium swelling (also referred to as peak swelling or maximum swelling) can extend for different film types and by choosing a lower swelling capacity (light red area in Fig. 2) [100]. Moreover, the region of equilibrium swelling (red region in Fig. 2) was shown not to be located in a single zone as previously thought, but is composed instead of several sub-regions within that area, making it difficult to determine if a solvent will fall within the peak swelling region [100]. It is remarkable that the limitations of the Teas chart have been emphasised continuously for over three decades $[100,103,108,111]$, while the concept is still presented in recent publications without a proper note of caution $[99,112,113]$.

Several attempts have been made to classify the swelling capacity of paints in organic solvents into a practical model using more elaborate models than the Teas chart $[2,104,106,109,114,115]$. However, these methods to predict paint swelling appear difficult to use, which may explain why the Teas diagram remains popular. Michalski [2] presented a model that fits many solvents into a three dimensional 'egg-shaped' graph [2]. However, some of the limitations of the Teas chart, such as the use of one parameter for both hydrogen donor and acceptor capacity are also inherent to Michalski's system [108] and the models has not become widely used.

Zumbühl [109] attempted to describe the equilibrium swelling capacity of 50 solvents on four types of artist paint using a combination of both $\delta_{h}$ and $\mathrm{E}_{T}^{N}$ with two solute-dependent factors used as 'fitting' parameters [109]. Although his model is based on an adaptation of the Abraham model, which was shown to have good prediction power for dissolution [91], the results are not significantly better than the Teas chart at predicting the swelling power of solvents on oil paints. As shown in Fig. 1a, swelling and leaching occur simultaneously and the dissolution of materials may influence the swelling capacity. Therefore, Zumbühls study illustrates well that solubility alone does not capture the full complexity of the combined solvent action that occurs when oil paint is exposed to solvents.

Many researchers have attempted to correlate swelling to solvent properties since this would be convenient for practical cleaning purposes [87]. However, the prediction of swelling proved only successful in certain sub-classes of solvents, which is not surprising since all models described above have the fundamental shortcoming that they are solely based on thermodynamics of solvent-solute interaction and do not account for polymer elasticity. A polymer swelling model accounting for polymer elasticity is the Flory-Rehner model, which is considered an accurate model to predict equilibrium swelling [116-118]. This model is based on the force equilibrium between osmotic pressure due to swelling (entropy-driven) and the counter-acting elastic pressure. This model has never been applied to describe swelling in oil paint, but because it offers a straightforward manner to add the effect of polymer elasticity, describing swelling with Flory-Rehner theory is desirable.

Besides neglecting polymer elasticity in the description of swelling, oil paint cleaning literature does generally not distinguish between equilibrium swelling and swelling kinetics. As a result, solvent transport phenomena are not accounted for. Due to the limited contact times encountered in cleaning practice, equilibrium swelling is generally only reached in the uppermost layer of the paint. It is therefore necessary to investigate how the equilibrium swelling relates to factors such as the rate of solvent diffusion and leaching of soluble paint components. In general, models such as the Teas chart do not properly describe solvent action (Fig. 1a) because they only consider thermodynamic 
(equilibrium) aspects of varnish solubility or equilibrium swelling of oil paint. They do not account for the rates of solvent swelling and desorption (due to evaporation and diffusion to the surface), and only poorly of solubility of internal paint components. Therefore, both thermodynamic aspects (such as solubility) and transport processes (such as solvent diffusion) should be modelled in order to get a complete theoretical description of solvent action. The feasibility of modelling these processes together is currently investigated by the authors.

\section{Experimental swelling studies}

The swelling of paint films in a range of solvents was studied by Browne in the 1950s [119-128], providing a useful classification of swelling power by solvent- and pigment type. In a detailed study of swelling and leaching ("Leaching" section), Stolow found that the swelling curves obtained for films that had never been treated by solvents (referred to as 'virgin' films), differed from preleached films by the absence of a distinct equilibrium after about $10 \mathrm{~min}$ in the swelling curve (Fig. 3) [87]. Virgin films showed a higher equilibrium swelling, reflecting the increased density of pre-leached samples, and turned out to be better reproducible [87]. These results indicate that swelling and leaching are strongly interconnected processes.

Research has been carried out on the effects of solvent mixing on swelling behaviour. Mixtures are often used to decrease the 'rapid action' of some strong solvents, meaning solvents in which aged varnishes are highly

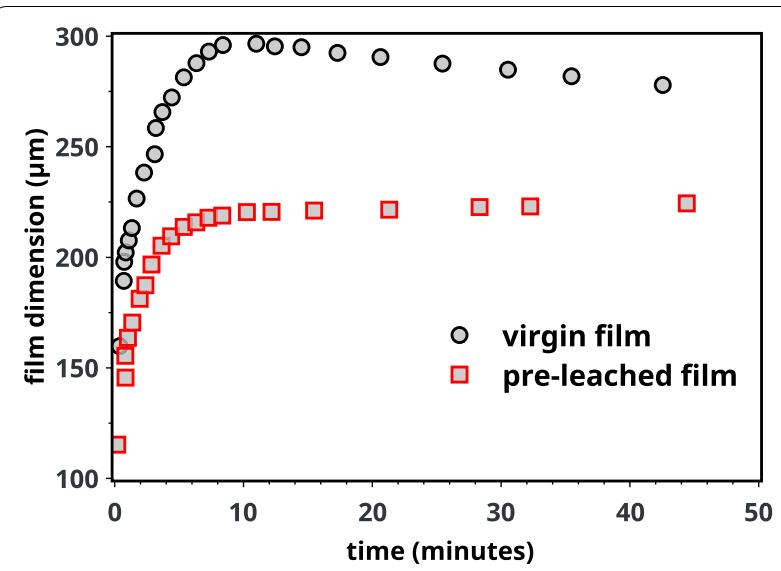

Fig. 3 Swelling curve for virgin (unexposed) and pre-leached films, reproduced from Stolow [87]. The virgin films swells to a distinct equilibrium around $10 \mathrm{~min}$ and decreases in swelling at longer timescales due to leaching. The equilibrium swelling is higher in the virgin film indicating densification due to leaching in the pre-leached film soluble. Although the concentration of the high swelling solvent decreases when a solvent with lower swelling capacity is mixed in, mixtures of solvents may increase swelling capacity as compared to pure solvents. Figure 4 shows the swelling in binary solvent mixtures of benzene- $n$-hexane and acetone-isooctane. At the time, this phenomenon was rationalised in terms of a close match between the Hildebrand total solubility parameter [93] of the mixture of solvents and the solubility parameter of the polymer (here considered as a solute) [87]. However, Phenix [110] later argued that older paints chemically differ from the young paint used by Stolow, since the former contain higher concentrations of oxidised functional groups, which would lead to different polymer solubility parameters. We note that rationalisation of equilibrium swelling purely based on Hildebrand solubilities may indeed fail, as the underlying theory does not account for polymer properties, as done in Flory-Rehner theory. Figure 4 also shows that the extent to which swelling occurs can depend strongly on the age and composition of the paint samples. Therefore, the results obtained from relatively young, lab-based films studied by Stolow, may not accurately reflect the swelling (and therefore leaching) in old master paintings.

More recently, Phenix systematically studied the swelling of unsupported paint films using a microscope [110, 129]. Special attention was given to the competing processes of swelling and leaching, which was found to be a major source of experimental errors. Phenix phrased this as follows: 'The processes of swelling and leaching are, in some respects, in competition: an increase in the dimension of a paint sample due to solvent sorption may be more or less countered by the contraction associated with loss of binder matter' [129]. This is an important observation, because strongly leaching solvents may have a low(er) swelling power, which is often the case for highly polar solvents (except water). Large differences in degree of swelling between different paint films were also found: especially iron oxide earth pigments showed moderate to high swelling capacity. Exposure to light was found to result in a lower degree of equilibrium swelling and a slower rate of swelling compared to their unexposed counterparts, possibly due to increased cross-linking [129]. Another interpretation could be that light exposure results in more autoxidation of the oil and therefore more leaching and lower swelling.

We conclude that, although the exact reason for the differences in degree of swelling between different paint films was not always identified, it is again clear that the properties of the polymeric structure of the binding medium (Fig. 1b, d, e) is a key factor that determines the swelling capacity of oil paints in organic solvents. 

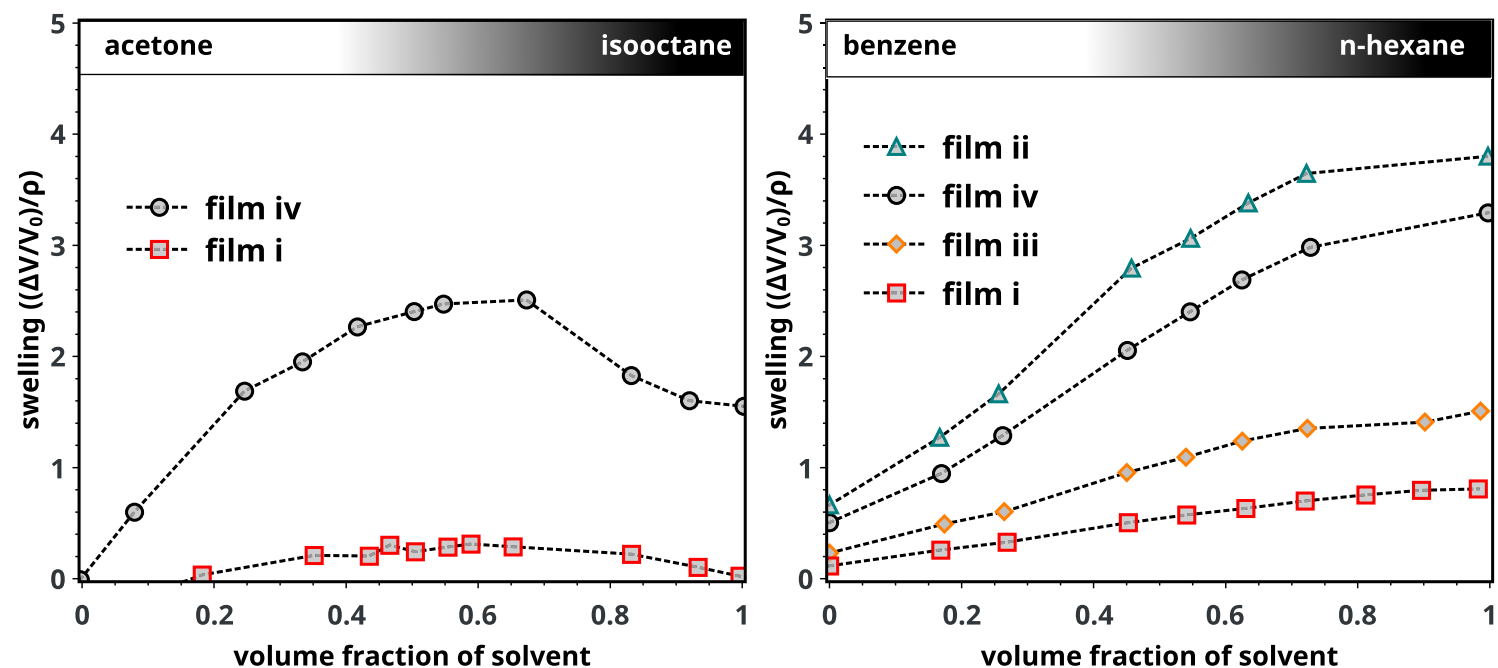

Fig. 4 Mode of swelling in binary solvent mixtures of benzene- $n$-hexane and acetone-isooctane, reproduced from Stolow [87]. Film (i): vacuum stand oil and $0.5 \%$ lead naphthenate, 7 weeks at $32^{\circ} \mathrm{C}$; film (ii): vacuum stand oil and $0.5 \%$ lead naphthenate, $72 \mathrm{~h}$ at $80^{\circ} \mathrm{C}$; film (iii): alkali refined linseed oil and $0.5 \%$ lead naphthenate, $72 \mathrm{~h}$ at $80^{\circ} \mathrm{C}$; film (iv): open pot stand oil and white lead pigment, 18 weeks at $32^{\circ} \mathrm{C}$. All films were pre-leached in acetone (film i-iii) or methanol (film iv). Swelling capacity expressed as volume change $\left(\Delta V / V_{0}\right)$ corrected for initial film density $\rho$ (density before the experiment)

\section{Solvent diffusion}

The polymeric structure of the binding medium is again an important factor for solvent diffusion in paint. Diffusion is a form of solvent transport that occurs in the open space between crosslinked polymer chains, sometimes called the 'inherent free volume of the polymer' [48]. According to Fick's law, diffusion is described by a concentration gradient and a diffusion coefficient. When there is no significant interaction between the polymer and the solvent, the diffusion coefficient does not depend on concentration and one finds so called ideal Fickian diffusion. Whether deviations from ideal Fickian behaviour occur, depends on the rate of relaxation of polymer chains compared to that of diffusion. Such deviations are called non-Fickian diffusion, for which several theoretical descriptions are available [48]. In order to incorporate solvents, the polymer generally needs to swell to a certain extent, resulting in concentration dependency of the diffusion coefficient. The possibility for swelling will depend strongly on the concentration of crosslinks, which determines the elasticity of the polymer network. It should be noted that pure diffusive transport only occurs in intact polymer networks (Fig. 1b, d, e). When cracks are present in the paint (Fig. 1c), convective transport in cracks will also occur at rates orders of magnitude larger than purely diffusive transport [2].

Recently, we used time-dependent ATR-FTIR spectroscopy to measure simultaneous solvent swelling and diffusion in model paint films [22]. Such an IR spectroscopic approach, where solvent swelling and diffusion are measured at the same time, provides additional insights in how different processes during cleaning are interconnected (Fig. 1a). To quantify the spectroscopic data, a model was developed that describes the solvent diffusion process including significant film swelling and nonFickian diffusion. This diffusion-swelling model describes the diffusion coefficient as an exponential function of the polymer volume fraction $\Phi$, which is a measure of the swelling of the polymer. It was possible to estimate diffusion coefficients, which increased considerably during swelling (Fig. 5). One important finding was that strongly swelling solvents diffuse faster than weakly swelling solvents. The relation between diffusion coefficient $\left(D_{\mathrm{eq}}\right)$ and equilibrium swelling $\left(f_{\text {eq }}\right)$ is displayed in Fig. 6. The diffusion-swelling model also offers the possibility to predict the solvent penetration in paints exposed to typically short solvent treatments, as will be shown in forthcoming work. Equilibrium swelling could in principle be predicted using the Flory-Rehner equation if the FloryHuggins interaction parameter (or Hildebrand solubility parameters) and the crosslink density of the network are known. Predictive models for the diffusion coefficient and its dependency on degree of swelling are virtually non-existant, underlining the practical relevance of accurately measuring these processes under controlled conditions.

The presence of pigments may influence solvent action. We studied the influence of $\mathrm{ZnO}$ pigmentation in the oil paint on swelling and diffusion and found no significant differences between pigmented and unpigmented films, 


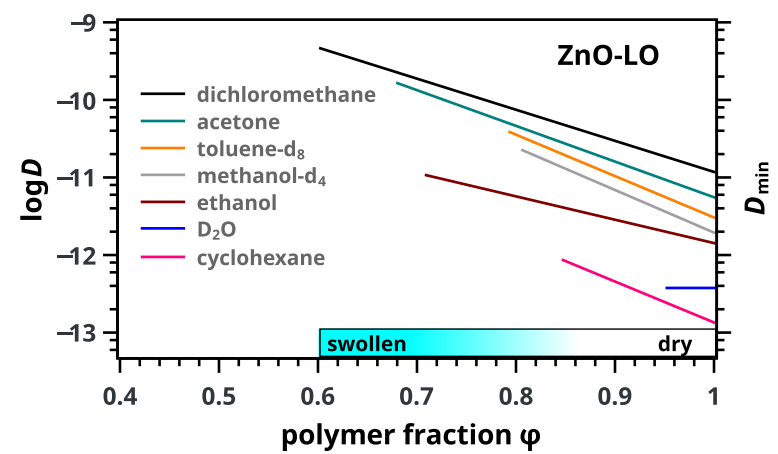

Fig. 5 Diffusion coefficient in a pigmented $\mathrm{ZnO}$ and linseed oil based paint ( $\mathrm{ZnO}-\mathrm{LO}$ ) versus polymer fraction $\Phi$, calculated using the diffusion-swelling model. The diffusion coefficient increases during swelling (decreasing $\Phi)$ [22]

likely due to relatively low PVC of $\approx 20 \%$ [22]. Since the polymerised drying oil is the only component that swells, the diffusion coefficient of solvents and the degree of swelling is dependent on the amount of oil present in the paint [75]. Paints with a higher oil content (low PVC) will therefore show a higher degree of swelling given that they contain a similar network structure. Liu found that the diffusion coefficients of water diffusing through alkyd coatings initially decreased with increasing PVC, reaching a minimum value at $60 \%$, and then increased with increasing PVC [130]. When the PVC was less than $60 \%$, the barrier property of pigment was the main factor affecting the water diffusion behaviour. However, at PVC values greater than $60 \%$, the formation of micro-voids around pigments allowed water to diffuse through these pores directly, leading to increasingly rapid diffusion [130]. Perera describes how PVC and water permeability depend on the presence of pigment-binder interactions. It was shown that a red lead $\left(\mathrm{Pb}_{3} \mathrm{O}_{4}\right)$ alkyd paint became much less permeable to water with increasing PVC, which was attributed to the formation of lead soaps [75]. The permeability of a $\mathrm{TiO}_{2}$ based alkyd paints was only weakly influenced by the $\mathrm{PVC}$ since $\mathrm{TiO}_{2}$ hardly interacts with the binder [75]. These results illustrate how different polymer structures (Fig. 1b-e) cause different diffusion behaviour, resulting in a different response to solventbased cleaning.

\section{Leaching}

When solvents diffuse into a paint layer, leaching or extraction of soluble paint constituents will always occur to some extent but will mostly go unnoticed by a conservator during cleaning. Conservation scientists have studied leaching in considerable detail [107, 131-138]. Gas chromatography mass spectrometry (GC/MS) has often been used to determine the chemical composition of the

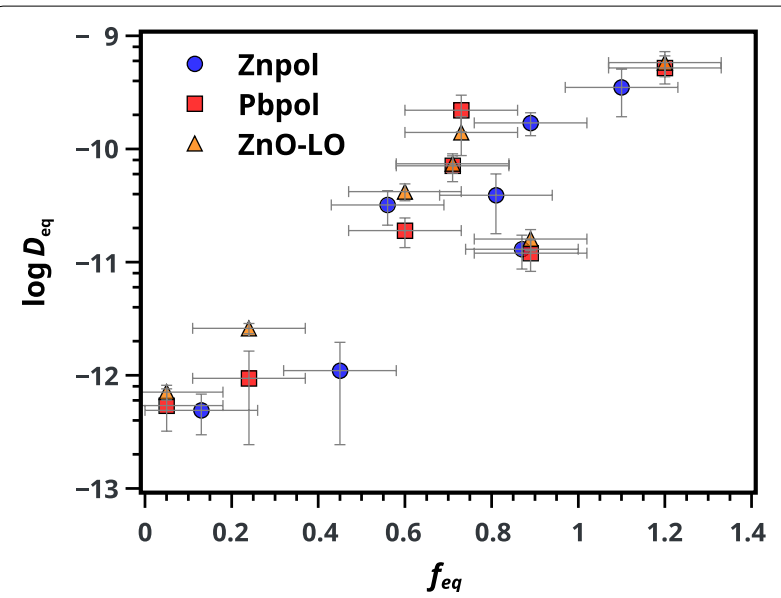

Fig. 6 Correlation of equilibrium swelling factor, $f_{\text {eq, }}$ with diffusion coefficient, $D_{\text {eq }}$ for three types of linseed oil based model paints. Znpol: zinc ionomer, Pbpol: lead ionomer and ZnO-LO: pigmented zinc white paint. Lower swelling generally shows slower diffusion [22]

leached materials [134]. The primary concerns related to the leaching of oil paint are:

1. Embrittlement due to the extraction of low-molecular-weight (LMW) components, which act as (secondary) plasticisers [11, 12, 131, 139-143].

2. Alteration of optical properties due to redistribution or removal of small molecules from the surface and formation of a surface haze $[23,144]$.

3. Disturbance of local chemical equilibrium which may lead to increased degradation reactions ("Solventmediated reactivity" section) [13].

It is known that linseed oil-based paint films can significantly increase in density after exposure to organic solvents [87], which has been attributed to the leaching of soluble components from the film. Depending on the age and type of film, up to $45 \mathrm{wt} \%$ of the material could be leached by solvent immersion (Fig. 7) [87]. Again, long leaching times of up to $120 \mathrm{~h}$ and the use of relatively young paint films make it difficult to asses the practical relevance of these particular results for cleaning.

However, leaching also occurs with short exposure times and in real paintings. Sutherland used GC/MS to compare the amount of leachable material between mechanically cleaned samples and samples cleaned with solvents using cotton swabs [135]. In most cases, a small but measurable proportion of soluble fatty acids was removed from the paint due to the swabbing with solvent [135]. Realistic solvent exposure times were also studied by Zumbühl, who investigated leaching in model paints using immersion times of 5, 10, 20 and $30 \mathrm{~s}$ [107]. It was concluded that with short interaction times, solvents 


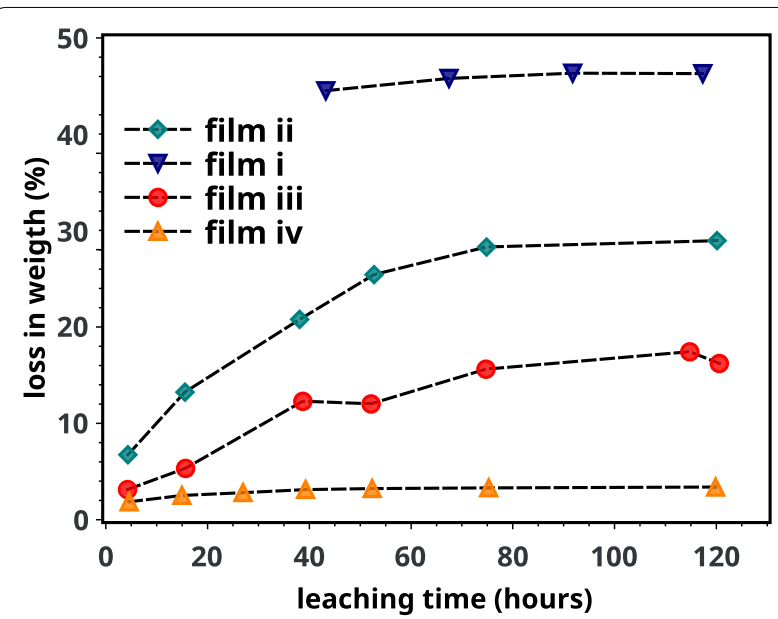

Fig. 7 Leaching by weigh in different solvents, reproduced from Stolow [87]. Film (i): open pot stand oil, 30 weeks at $32{ }^{\circ} \mathrm{C}$, methanol; film (ii): vacuum stand oil and $0.5 \%$ lead naphthenate, 30 weeks at $32^{\circ} \mathrm{C}$, methanol; film (iii): open pot stand oil, $17 \mathrm{~h}$ at $80^{\circ} \mathrm{C}$, acetone; film (iv): open pot stand oil and white lead pigment (81 wt\%), 46 weeks at $32^{\circ} \mathrm{C}$, methanol

with lower vapour pressure leached less material than solvents with a high vapour pressure [107]. The rationalisation given by Zumbühl using the vapour pressure on the leaching rate is problematic, as it confuses equilibrium thermodynamic effects with kinetic effects. Conducting experiments relating solvent vapour pressure to the rate of solvent diffusion, swelling, evaporation and dissolution are needed to investigate this effect.

The effects of leaching on the long-term physical stability of oil paint is not widely studied. However, shortterm effects on the physical properties, such as paint stiffness, are more easily measured and more abundantly reported. The physical influence of solvent exposure on the viscoelastic properties of oil paint was investigated using dynamic mechanical analysis (DMA) and differential scanning calorimetry (DSC), which demonstrated that leaching results in embrittlement and densification of paint $[6,11,81,140]$. It was found that polar solvents such as ethanol or acetone caused more embrittlement than apolar solvents such as cyclohexane with the same immersion time $[11,140]$. Besides the differences in solubility of paint components in different solvents, this effect can be explained by the fact that ethanol or acetone are much faster diffusing solvents than cyclohexane [22], resulting in further solvent penetration and the extraction of larger amounts of plasticisers. An example of the embrittlement of paint due to solvent exposure is given in Fig. 8, showing that $60 \mathrm{~s}$ immersion in acetone can induce a stronger increase in brittleness when compared to 126 days ageing at $50{ }^{\circ} \mathrm{C}$ [141]. When a pre-leached paint was immersed in solvent after 25 years of natural ageing,

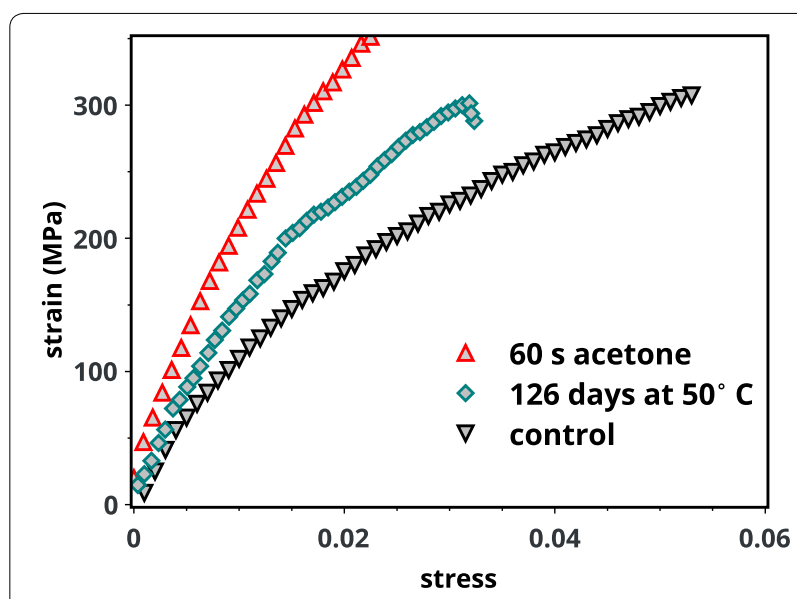

Fig. 8 Stress versus strain plots of commercial titanium white paint made with alkali refined linseed oil, reproduced from Mecklenburg [141]. The tests were conducted at $48 \% \mathrm{RH}$ and $23^{\circ} \mathrm{C}$, after the paint had been exposed acetone for $60 \mathrm{~s}$ and allowed to dry

renewed extraction of soluble components was observed [134]. The continued leaching upon solvent exposure stresses the importance of considering oil paintings as metastable objects that continually undergo slow chemical alterations. Therefore, the disturbance of local chemical equilibrium by cleaning interventions may affect the rate of degradation processes and lead to unwanted chemical alterations on longer timescales. Such effects are discussed in "Solvent-mediated reactivity" section.

The influence of leaching on the mechanical properties of oil paints have also been studied in real paintings. Using an NMR MOUSE [145] (Mobile Universal Surface Explorer), Fife et al. [12] measured and compared the stiffness of two paintings from the same artist and time, one of which had never been cleaned and one that had been repeatedly exposed to organic solvents. The NMR MOUSE can be used for the non-destructive analysis of large objects and is used to measure the quantity of proton containing materials (amplitude, $\mathrm{T}_{1}$ ) and the stiffness of the polymer network (rate of transverse relaxation time decay, $\mathrm{T}_{2}$ ). In this study, it was shown that the painting that had undergone varnishing and numerous solvent-based varnish removals was significantly stiffer (larger $T_{2}$ ) throughout the depth of the painting [12]. This increased paint stiffness was attributed to the solvent-extraction of LMW components [12]. Since oil paint may also age differently in absence of varnish in the first place, it remains difficult to confirm to what extent the increased paint stiffness was indeed due to leaching. A major drawback of the NMR MOUSE as a tool in cleaning studies is the limited time- and depth resolution, which does not allow monitoring the uptake of rapidly diffusing solvents in thin paint layers. However, 
the magnitude of the transverse relaxation time before and after the cleaning procedure can be compared to reveal changes in brittleness [143]. Prati et al. used this method to determine the influence of several green solvents (released by gels) on the stiffness of oil paints and found that $\gamma$-valerolactone and ethyl lactate can produce rapid and strong changes in the paint layer due to leaching [143]. They also determined the retention of several solvents in paint, discussed in "Solvent evaporation and retention" section.

The chemical composition of the leached material (sometimes referred to as 'leachate') is generally used to evaluate the state of oil paint degradation. A large corpus of scientific literature is available on the composition of the leached materials [133, 146-148]. Due to the complex autoxidation chemistry of unsaturated triglycerides, the composition of the leached material is complex and diverse. It is important to be aware of the assumptions most leaching studies make:

- characterising the extract (components not linked to the polymer network), provides accurate information on the autoxidation chemistry of the remaining polymer network

- more strongly degraded oil networks lead to more polar extractables.

Although these assumption have not been thoroughly investigated, recent studies suggest that there is indeed a correlation between degree of carboxylic acid formation [32] within the network and an increased amount and polarity of extracted species [149]. Nevertheless, it is important to realise that the information on the network structure from leaching experiments is obtained indirectly and may not reflect the combined influence of solvent action on the remaining polymerised oil network.

In most older leaching studies, gas chromatography mass spectrometry (GC/MS) was typically used without pyrolysis, while more recently $[147,148,150]$ pyrolysis GC/MS was used with thermally assisted hydrolysis and methylation (often called THM-GC/MS or THM-PyGC/MS). In THM-Py-GC/MS studies, triacylglycerides (TAGs) are converted (derivatised) into fatty acid methyl esters (FAMEs). Derivatisation into FAMEs is necessarily done in GC/MS experiments to detect the fragments. However, information on the size of the fragments is lost in the derivatisation: one does not observe intact TAGs or small polymeric fragments, only FAMEs $[147,148,150]$. The most abundant compounds found in extracts from oil paintings are carboxylic and dicarboxylic acids. In the autoxidation process of TAGs, cleavage of $\mathrm{C} 16-\mathrm{C} 18$ fragments leads to the formation of $\mathrm{C} 8-\mathrm{C} 10$ fragments. As a result, suberic (di-C8, octanedioic) acid, azelaic (di-C9, nonanedioic) acid, sebacic (di-C10, decanedioic) acid are often detected in addition to palmitic acid (C16:0) and stearic acid (C18:0) $[148,151]$. Due to the complexity of the leached materials, separation techniques such as liquid chromatography (LC) are often used and combined with soft MS techniques such as electrospray ionization (ESI). Van Dam et al. used LC-ESI-MS to identify a great variety of oxidation compounds of TAGs [152]. Modugno et al. used HPLC-ESI-MS to study the effects of relative humidity on the composition of extracts and found that ageing at high RH conditions resulted in increased extraction of dicarboxylic acids compared to ageing at low RH conditions [149]. Following up on Van den Berg et al. [147], La Nasa et al. presented an analytical GC/ MS method for the analysis of mixtures of free fatty acids and metal soaps in paint samples using selective silylating agents [153]. This method can discriminate between regular free FAs and FAs derived from metal soaps using quantitative GC/MS analysis [153].

It should be noted that the use of mass spectrometry to study paint extracts always leads to the detection of soluble paint components because mass spectrometry is incredibly sensitive. This sensitivity raises the important question when leaching becomes problematic, which is especially difficult to predict on longer timescales. In principle, it may be possible to extract non-crosslinked components from a paint without significantly altering the properties or physical stability of the polymer network. Therefore, leaching studies should ideally be combined with another measure of the effects of solvent action, such as chemical reactivity inside the remaining paint ("Solvent-mediated reactivity" section).

\section{Solvent evaporation and retention}

During solvent action, some solvent inevitably remains inside the paint layer for a certain period of time; this time is called retention time. The retention time of solvents is governed by the rate of solvent transport inside the paint ("Solvent diffusion" section) and the rate of evaporation form the paint surface. Quantitative information on the retention time of common cleaning methods or solvents can contribute to better assess the risks associated with solvent cleaning.

Stolow showed that the rate of solvent sorption $\left(k_{S}\right.$, uptake) is faster than desorption $\left(k_{D}\right)$ and the two rates are related by $k_{D} / k_{S} \approx 0.65$ for all solvents except benzene [87]. This effect needs scientific attention. Nowadays, such effects can be predicted using theoretical modelling of solvent transport and evaporation in paint. Since the 1990s, work by Masschelein-Kleiner is frequently cited regarding solvent retention studies [154]. In this work, solvents were applied on mock-up paint samples and the retention time of a range of solvents was 
determined gravimetrically. Short retention times were found for the majority of saturated hydrocarbon solvents, as well as most halogenated solvents, benzene, toluene and ethyl- and isopropyl ethers [154]. More recently, solid phase microextraction (SPME) was used to determine the percentage of solvent retained in the paint after simulated cleaning treatments [155]. Combining SPME and NMR-MOUSE, Prati et al. showed the relation between paint softening and retention of solvent [143]. Depending on the type of solvent, the presence of solvent could be detected with SPME for several hours up to several days, showing the long-lasting plasticising effect of highly retentive solvents such as benzyl alcohols. For some solvents, the stiffness of the paint after the solvent was fully evaporated was shown to increase compared to the stiffness before solvent exposure, due to leaching [143].

We recently used a newly developed portable Fourier Transform laser speckle imaging (FT-LSI) setup to quantitatively study the dynamics of solvent penetration during cleaning at a high frame-rate [156]. The FT-LSI setups allowed the study of solvent diffusion/evaporation rates and the total solvent retention time. In addition, qualitative spatial information on the spreading and homogeneity of the applied solvent was obtained. It was shown that LSI can detect the presence of ethanol in oil paint for more than $20 \mathrm{~h}$ after saturation with solvent. In a series of measurements with increasing $\mathrm{RH}$, a strong increase in dynamics at humidities above $40 \%$ was observed, underlining the great sensitivity of LSI for measuring solvent retention inside oil paints. A set of samples that was subjected to accelerated ageing at high $\mathrm{RH}$ were tested, as well as samples with different varnish thickness, different solvent application times, solvent application methods and a range of different solvents. It was found that solvents diffuse more in lateral direction and are retained in aged samples for a shorter period. Furthermore, it was found that varnishes temporarily hinder solvent diffusion into the paint. Different methods of solvent application showed different solvent retention and homogeneity after application [156].

\section{Solvent-mediated reactivity}

The exposure of oil paint to solvents results in the penetration and retention of solvents inside the paint, which leads to paint swelling and the extraction of soluble paint components. Because solvents may be retained inside paint layers for prolonged periods of time, this raises the question what the influence of the presence of (small amounts of) solvents on chemical reactions inside the paint layer could be. This topic has been a central topic in our research group but received little attention by others. Apart from changes in physical properties of the paint bulk and optical properties at the surface, solvent action may result in the migration (redistribution) of soluble components between paint layers. The migration of soluble paint components can enhance the rate of degradation reactions inside oil paint when the paint is swollen with solvents. In order to understand the local chemical changes due to this migration process, it is important to understand the molecular mechanisms by which paintings degrade. The two most studied chemical processes in oil paint that could be affected by the use of solvents or water are: (1) hydrolysis of TAGs of the oil binder and (2) (crystalline) metal soap formation. Hydrolysis is an important pathway that leads to the release of high concentration of free SFAs in an oil paint. Alternatively, SFAs may be present as additives in modern oil paints or could have been added due to wax-resin lining with beeswax, which contains significant quantities of SFAs. If both high concentrations of free SFAs and metal ions are present, crystalline metal soaps are formed readily [69], making hydrolysis and metal soap formation intimately related.

\section{Fatty acid migration and metal soap formation}

Crystalline metal soaps are a serious problem in oil paint conservation because they often lead to the formation of protrusions, crystalline material deposits on the surface and increased transparency of paint layers [8].

To investigate if solvent-exposure can have an effect on slow chemical alterations in paint, we studied the effects of solvents on metal soap crystallisation in ion-containing linseed-oil based model systems [69]. These model systems mimic the situation where the common white pigments lead white $\left(2 \mathrm{PbCO}_{3} \mathrm{~Pb}(\mathrm{OH})_{2}\right)$ or zinc white $(\mathrm{ZnO})$ have released lead or zinc ions into the binding medium and ionomeric metal carboxylates are formed [40]. These ionomeric metal carboxylates can exchange with SFAs to form crystalline metal soaps (complexes of metal ions and long chain saturated fatty acids). In our study, the reaction of ionomeric metal carboxylates with externally provided SFAs to form crystalline metal soaps was investigated in both pigmented and unpigmented (ionomer) model paints [69]. A custom-made reservoir containing SFAs dissolved in acetone was used to deliver the SFAs to the model paints. It was concluded that the exposure of ionomeric metal carboxylates to SFAs in solution is a sufficient condition for rapid metal soap formation. In addition, the transport rate of SFAs was found to be significantly enhanced by solvent-swelling and the presence of traces of water [69]. It was previously found that the rate of metal soap crystallisation decreases rapidly with the degree of linseed oil polymerisation, leading to amorphous metal soaps that are 'kinetically trapped in a semi-crystalline state' [157]. Even if no SFAs need to be displaced, it may therefore be possible that solvent 

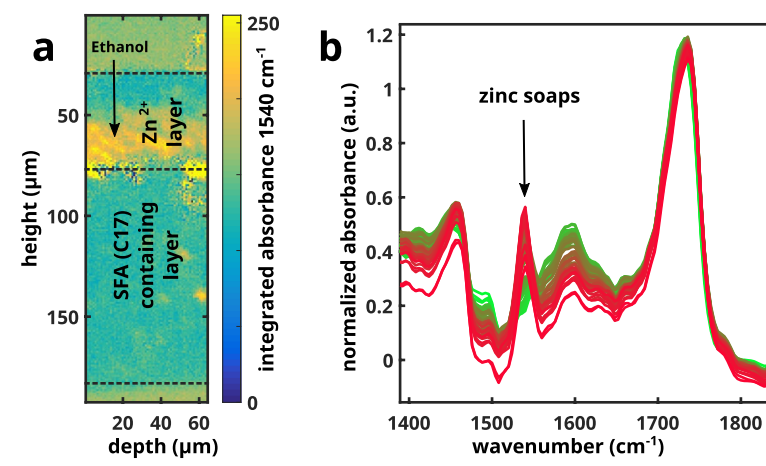

Fig. 9 a Imaging ATR-FTIR map showing the distribution of crystalline zinc soaps $\left(1540 \mathrm{~cm}^{-1}\right)$ in bilayer paint model after 30 min ethanol exposure using Evolon CR without controlled solvent loading. The zinc carboxylates containing top layers clearly showed the formation of zinc crystalline zinc soaps, which had been introduced by the SFA (C17) containing bottom layer due to ethanol exposure (direction of solvent flow indicated with arrow). $\mathbf{b}$ Corresponding color-coded FTIR spectra: red is at the bottom of the zinc containing layer, green at the top. Image reproduced from [13]

swelling can also enhance the rate of metal soaps crystallisation by temporarily lowering the effective crosslink density due to swelling.

Knowing that solvent-swelling can lead to the migration and reaction of SFAs, we studied the extraction of a SFA marker (margaric acid, C17) and monitored the formation of zinc soaps as a measure of 'impact' of solvent cleaning [13]. Tailored bilayer model systems based on polymerised linseed oil, consisting of a C17 containing bottom-layer and a zinc ions containing top-layer, were used. Upon solvent exposure, the migration of $\mathrm{C} 17$ into the top-layer and subsequent metal soap formation could be tracked. Three methods of solvent application were compared: cotton swab, rigid gel and Evolon CR tissue (with different solvent loading) [13, 158]. It was concluded that both swab cleaning and the application of Evolon CR tissue without controlled solvent loading, result in comparable SFA extraction. The rigid gel and Evolon CR with controlled solvent-loading limit the amount of SFA extraction [13]. Although redistribution of the $\mathrm{C} 17$ marker took place in all cases where solvent was applied, crystalline zinc soap formation was not observed after 5 min of ethanol exposure. In contrast, significant zinc soap formation was found after 30 min of ethanol exposure using Evolon CR tissue without controlled loading (Fig. 9) [13]. These results show that the redistribution of SFAs between paint layers and their reaction with metal carboxylates to form crystalline metal soaps can be enhanced by prolonged solvent exposure. However, it was also found that the differences observed after 5 min of solvent exposure using any of the studied methods did not lead to increased amounts of zinc soaps on longer timescales [13]. Compared to no solvent exposure in the blank, the differences in zinc soap formation were not significant 7 months after the experiments. These results show that the rate of SFA migration and zinc soap formation can be, even without solvent exposure, relatively fast if sufficient concentrations of free SFAs and zinc carboxylates are present. In that case, the influence of solvent exposure on zinc soap formation could not be detected.

\section{Environmental humidity}

Compared to the relatively stable environmental humidity conditions in museums [159], the use of aqueous solutions for surface cleaning of paint results in high concentrations of water on relatively short timescales. It has thus far remained difficult to assess the risks involved with aqueous surface cleaning and how the risks of aqueous treatments compare to high $\mathrm{RH}$ conditions.

To investigate the effects of environmental conditions that likely promote ester hydrolysis in oil paint, the authors recently studied the effects of high $\mathrm{RH}$ on the autoxidation and ester hydrolysis in TAGs and the resulting formation of amorphous zinc carboxylates (COOZn) [32]. A strong increase in COOZn was observed at $77 \% \mathrm{RH}$ compared to $12 \% \mathrm{RH}$ due to an accelerating effect of water on autoxidation. No hydrolysis was observed under the conditions studied, suggesting that oil paints are, in the initial stage of curing, rather resistant to hydrolysis. Considering the slow diffusion of pure water in oil paint [69] and comparably slow moisture diffusion alkyd paint [50], the moisture levels inside the paint layers at $77 \% \mathrm{RH}$ for a week are likely more significant than the levels encountered during aqueous-based surface dirt removal. Therefore, the risks of enhancing the rate of hydrolysis of TAGs with the short exposure times typically used in aqueous cleaning methods, are likely to be limited. It should be noted that ester hydrolysis alone does not capture the full complexity of the risks involved with aqueous cleaning, which include possible pigment pickup and the solubility of organic dyes.

\section{Modern materials for cleaning}

Aiming for increasingly controlled application of solvents during cleaning, the focus of cleaning science has shifted from the measurement of swelling in the 1950s, towards the development and testing of solvents confined in emulsions and gels from the 1990s onwards [3, 38, 160-165]. A gel is defined as a 'Non-fluid colloidal network or polymer network that is expanded throughout its whole volume by a fluid' [166]. Thickened solvents and gelled systems aim to reduce the mechanical action necessary for surface cleaning and provide the conservator 
with 'superior kinetic control' of the cleaning process $[167,168]$. In this context, gels are often called 'retentive', referring to the concept that they are supposed to retain the solvent more compared to a neat solution. The is an entirely different phenomenon ("Solvent evaporation and retention" section). The confinement of solvents is thus proposed to reduce the rate of solvent diffusion into the paint, thereby limiting solvent action. With respect to the reduced solvent delivery rate by gels, it should be mentioned that one deals with two coupled solvent transport processes: one inside the gel, which determines the release rate of solvent by the gels, and one inside the paint. The relative rate of these two processes will determine if any 'superior kinetic control' compared to applying a pure solvent can be achieved with a gel.

Gels are commonly divided into two classes:

- Chemical gels, having covalent chemical bonds between monomers (subunits). These gels may come pre-made and only need soaking in the solvent of choice before application.

- Physical gels, having non-covalent interactions between monomers $[161,169]$. These gels can either be mixed with solvent and spread on the surface directly, or come as powders that need to be mixed or heated to form the gel.

Physical gels are often called 'spreadable gel' or 'thickener' because they are applied by spreading them on the area to be cleaned. Examples of physical gelling agents are Carbopol $\odot$ (polyacrylic acid), Ethomeen $\odot$ (coco amine ethoxylates), Pemulen $\odot$ (copolymers of acrylic acid and alkyl acrylate crosslinked with allyl pentaerythritol) and polyvinyl-alcohol-Borax (often called moldable gels) [6, 38, 170-173]. These gels can be used with small amounts of water and the gel itself can have active cleaning properties. For example, the Pemulen` gels can form oil-inwater $(\mathrm{OiW})$ microemulsions with hydrocarbon solvents. The lipophilic part adsorbs at the oil-water interface and the hydrophilic part swells in the water forming a gel network. Although the phenomenon is not yet completely understood, the presence of both lipophilic and hydrophilic functional groups in one gel can enhance the cleaning properties compared to free solvents.

Polysaccharide-based gelling agents belong to the oldest and most widely available gelling materials and are physical gels because they are held together by hydrogen bonds. Examples of polysaccharide-based gels are Gellan [174], agar [175, 176], and Klucel@ G, (hydroxypropyl cellulose). By increasing the concentration of agar in solution, the gel becomes more rigid and the pore size and rate of water diffusion decreases [177]. Because the diffusion of water is restricted [177] within the polymer network of these gelled systems, they can be used as slow releasing containers for the application of aqueous solutions. Although generally used with water, is also possible to load polyscharide gels with relatively polar solvents such as ethanol or acetone [178] or possibly with OiW microemulsions [179]. Agar, and presumably other more rigid gels, can also be used grated by brushing small pieces of agar on an unvarnished paint surface [180].

A disadvantage of physical gels is that they have to be cleared after application using free solvents and cotton swabs or sponges to avoid gel residues, thereby exposing the surface to additional solvent and mechanical action. Gel residues $[160,181]$ are hardly avoidable, especially for highly porous paints. Residue studies are an important part of cleaning studies dealing with the use of modern materials and it is generally assumed that residues should be avoided. However, the effects that residues may have on paint films in the future remain largely unknown, making this a particularly challenging topic in terms of risk assessment. Recently, an investigation of options for surface cleaning unvarnished water-sensitive oil paints was carried out, with particular attention to residues [70]. In one case, a correlation between traces of silicone emulsifiers and the formation of crystalline zinc soaps could be made based on ATR-FTIR analysis [70], showing that silicone residues can increase the time that paints remains plasticised. It remains to be investigated if the prolonged plasticisation directly caused the increased formation of crystalline zinc soaps observed in the experiment. Strategies that aim to reduce gel residues by using polysaccharide gels loaded with cleaning solvent on an impregnation tissue and removing the gel with an absorbing tissue have been developed [182]. However, an additional clearance step is still required.

Chemical gels exhibit improved mechanical properties compared to physical gels; they can be shaped into a desired form and can swell in a liquid without gel solubilisation. Furthermore, the risk of having gel residues is reduced compared to physical gels due to the presence of covalent crosslinks [161]. Acrylamide-based chemical gels have been suggested as a residue-free alternative to the widely applied physical gel methodology [183]. Semi-interpenetrating polyhydroxyethylmethacrylate (pHEMA) and polyvinylpyrrolidone (PVP) chemical gels (marketed as Nanorestore $\odot$ ) are polymer blends. Although hydrogen bonds between the carbonyl group of PVP and the hydroxyl group of HEMA exist, the network consist of two types of linear polymers that are linked by covalent bonds between monomers [161]. Domingues et al. studied the water release of PVP/HEMA gels on paper by mass analysis and found that the water release of the newly developed rigid gels was significantly lower than that of the polysaccharide gels agar and gellan (at 
$3 \mathrm{wt} \%)$ or acrylamide based gels [184]. It is important to note that although these gels were marketed for the use on painted surfaces, the water release was tested on a paper substrate, which will have a profound effect on the rate of solvent sorption by the surface. The higher 'retention' that was found may therefore be invalid for oil paint surfaces. One recent study used quasi-elastic neutron scattering (QENS) to study the polymer and water dynamics in pHEMA chemical and physical hydrogels at various water contents. It was found that, at a molecular level, physical gels show a slower water relaxation process compared to their chemical gel equivalents, likely as a result of side chains involvement in the formation of the three-dimensional network [185]. It was not made explicit how this result translates to water release during practical gel application on painted surfaces. A comprehensive overview of novel materials and methods for cleaning is given in the in the Gels in the Conservation of Art conference proceedings book [21] and the book 'Nanotechnologies and Nanomaterials for Diagnostic, Conservation and Restoration of Cultural Heritage' by Baglioni et al. [20].

The rate of water release by gels is not always lower compared to traditional methods of solvent application such as cotton swabs. NMR MOUSE experiments on acrylic emulsion paints showed that the amount of water delivered into the paint by agar gels was equal to swab cleaning. Other gels showed larger amounts of water required for the total cleaning action than pure swabs, which was often due to the need for a clearance step to avoid residues [163]. A similar conclusion was recently presented by Moretti et al., concluding that NMR measurements collected before, during, and after wet-cleaning tests proved that the use of an aqueous Klucel@ G gel did not significantly minimise the water penetration and swelling compared to swabs with free solvent [186]. In contrast, combined mass analysis and NMR experiments on oil paint mock-ups demonstrated a decreased uptake of solvent by the paint when using gelled systems [12]. A decreased release of solvent to the paint surface compared to swabbing was also found using ethyl lactate confined in a polyhydroxybutyrate gel. [143] It thus seems that there are considerable differences in the rate of solvent uptake in paint when using gels, which is likely explained by the variation in solvent transport rates expected in different polymerised oil networks (Fig. 1bd) encountered in paintings.

In this context, the authors used time-dependent ATRFTIR to study the kinetics of solvent delivery of three cleaning gels on model systems for intact oil pant binding media. [187] These model systems were polymers based on a polymerised linseed oil matrix with $\mathrm{Zn}^{2+}$ and $\mathrm{Pb}^{2+}$ ions included as an integral part of the network; similar to aged oil binding medium in paintings without cracks (for example Fig. 1b) [40, 188]. The diffusion of organic solvents and water into linseed oil based ionomers was found to be of similar magnitude for both free solvents and solvents released by gels, indicating that the solvent uptake by non-porous linseed oil based ionomers is relatively slow compared to the rate of solvent release by the gels [187]. This result demonstrates that the advantages of gel cleaning in terms of reduced solvent uptake by the paint are strongly dependent on the surface that is cleaned and the application time. When only judging solvent delivery rate inside the paint, the largest benefit of the use of gels is likely when cleaning porous substrates with a short application time. However, the advantages of reduced mechanical action of gels compared to swab cleaning remain relevant on any substrate.

\section{Conclusions and outlook}

The use of organic solvents on oil paint surfaces causes simultaneous solvent swelling, -diffusion, -evaporation, -leaching and solvent-induced chemical reactions, altogether defined as solvent action. Solvent action on oil paint includes both temporary chemical and physical changes, such as swelling and an increase in the rate of FA migration and metal soap formation, as well as permanent changes, such as the leaching of LMW components, or an increase in the brittleness of the paint. Using the words of Gilson, both cleaning and not cleaning are ways to 'let a painting perish.' Therefore, the only way to resolve this dilemma is to work towards a reliable assessment of the risks involved in cleaning by creating a thorough understanding of the physicochemical process involved in solvent action.

We discussed the processes that play a role in solvent action and presented the current status in the theoretical description of these processes. It was explained that cleaning often involves a complex mix of these processes, which nevertheless deserve separate theoretical descriptions. Although literature from polymer chemistry can be of great relevance for studying solvent action, not all areas in cleaning science have absorbed proper knowledge from the scientific community outside art conservation. Solubility theory is well accounted for and is adequately applied to dilute solutions. However, we conclude that the important phenomenon of paint swelling, which requires accounting for polymer properties, is not yet addressed using state-of-the-art theory and recommend the Flory-Rehner model to describe equilibrium swelling. Moreover, equilibrium swelling and swelling kinetics are often not distinguished. Swelling kinetics demands simultaneous treatment of swelling and diffusion. We recently developed a swelling-diffusion model that can provide 
the theoretical basis to additionally simulate leaching, evaporation and solvent retention based on the knowledge of swelling and diffusion in paint films. To start describing solvent action in the future, the swellingdiffusion model should be combined with models for mass transport across the paint surface using thermodynamic models describing the vapour- and liquid-liquid equilibrium at the surface.

Although solvent action is very complex, the processes involved in solvent action are directly linked to the properties of the polymeric oil binding medium. The chemical and physical properties of this polymer depend on the material composition and the environmental conditions during the drying and ageing of the paint. In cleaning science, polymer properties of the binding medium are often discussed in terms of solvents sensitivity. However, solvents sensitivity is merely a manifestation of influence of (in)organic pigments on the autoxidation chemistry of the oil, resulting in various types of polymeric binding media. These types of polymeric binding media determine to what extent solvent action can occur during cleaning treatments. Cleaning research could therefore focus on techniques that can relate polymer properties of the binding medium to solvent transport processes. Both theoretical and experimental work is needed to further develop the relation between polymeric structure and solvent action and estimate when solvent exposure may lead to unacceptable risks.

To advance our understanding of solvent action on the molecular level, analytical methods that can monitor the possible changes in chemical composition of an oil paint upon solvent exposure are required. Ideally, one would combine quantitative and spatially-resolved information on solvent transport with chemical information on reactivity. Such an experiment may be possible with timedependent FTIR imaging in transmission mode, where both solvents and potential degradation products are measured quantitatively and spatially-resolved. In order to integrate forthcoming cleaning research more closely into conservation practice, the focus should be on developing methods to monitor cleaning action in real time. To enable a comparison of cleaning methods or solvents on real paintings, these methods should be quantitative, portable and able to deal with heterogeneous paint surfaces. In addition, the instrumentation should feature an intuitive interface and should be easy to operate for conservators. Lastly but very importantly, data processing and interpretation should be fast (preferably on-the-fly) and should not require a software programming background. As an example, FT-LSI was presented as a powerful, quantitative and portable imaging technique for the study of solvent retention during oil paint cleaning and showed its potential for future use in the conservation studio.

The large number of publications focusing on novel materials for solvent application have provided important insights that can result in a reduction of the amount of solvent that is needed for cleaning. These materials can be used to their full advantage when the solvent diffusion rate out of the gel is the rate limiting factor. This is the case for porous and cracked paint surfaces where solvent transport inside the paint will be fast compared to solvent release by the gel. The potential of gelled systems to reduce mechanical action can provide an added benefit on any paint surface. In the development of novel materials for cleaning, gelled systems that allow precise tuning of solvent polarity are greatly desirable. To that end, gels with increased capacity for apolar solvents or microemulsions containing largely apolar solvents could be further developed or adopted from other fields such as cosmetics or coatings industries.

\begin{abstract}
Abbreviations
2D-IR: Two-dimensional infrared spectroscopy; ATR-FTIR: Attenuated total reflection fourier transform infrared spectroscopy; COOR: Ester; COOM: Metal carboxylate; COOZn: Zinc carboxylate; CPVC: Critical pigment volume concentration; DMA: Dynamic mechanical analysis; DSC: Differential scanning calorimetry; C17: Margaric acid; FAME: Fatty acid methyl ester; (HP)LC-ESI-MS: (High pressure) liquid chromatography electrospray ionization mass spectrometry; In-Air-PIL: In-air plasma-induced luminescence; LMW: Low molecular weight; LO: Linseed oil; LSI: Laser Speckle Imaging; NMR-MOUSE: Nuclear magnetic resonance mobile universal surface explorer; pHEMA: Polyhydroxyethylmethacrylate; PVP: Polyvinylpyrrolidone; PVC: Pigment volume concentration; QENS: Quasi-elastic neutron scattering; SAWN-MS: Surface acoustic wave nebulization mass spectrometry; SFA: Saturated fatty acid; SPME: Solid phase microextraction;TAG: Triacylglyceride; THM-Py-GC/MS: Thermally-assisted hydrolysis and methylation pyrolysis gas chromatography mass spectrometry; TMAH: Tetramethylammonium hydroxide.
\end{abstract}

Acknowledgements

The authors are grateful to Gwen Tauber, Laura Raven, Agata Graczyk and Alan Phenix for useful discussions.

Author' contributions

LB wrote the manuscript, all authors reviewed the manuscript. All authors read and approved the final manuscript.

Funding

This research is carried out within the framework of the NANORESTART project funded by the European Union's Horizon 2020 research and innovation program under agreement No. 646063. Additional financial support was provided by the Bennink Foundation/Rijksmuseum Fonds.

Availability of data and materials

Not applicable.

Competing interests

The authors declare that they have no competing interests.

Author details

${ }^{1}$ Van 't Hoff Institute for Molecular Science, University of Amsterdam, Science Park 904, PO Box 94157, 1090GD Amsterdam, The Netherlands. ${ }^{2}$ Conservation and Science, Rijksmuseum Amsterdam, Museumstraat 1, PO Box 74888, 
1070DN Amsterdam, The Netherlands. ${ }^{3}$ Conservation Department, TATE Gallery, Millbank, London SW1P 4RG, UK.

Received: 15 February 2020 Accepted: 23 April 2020 Published online: 06 May 2020

\section{References}

1. Gilson E. Painting and reality. A.W. Mellon lectures in the fine arts. New York: Pantheon Books; 1959. p. 484.

2. Michalski S. A physical model of the cleaning of oil paint. Stud Conserv. 1990;35(sup1):85-92. https://doi.org/10.1179/sic.1990.35.s1.020.

3. Khandekar N. A survey of the conservation literature relating to the development of aqueous gel cleaning on painted and varnished surfaces. Stud Conserv. 2000;45(sup3):10-20. https://doi.org/10.1179/ sic.2000.45.53.003.

4. Phenix A, Sutherland K. The cleaning of paintings: effects of organic solvents on oil paint films. Stud Conserv. 2001;46(sup1):47-60. https:// doi.org/10.1179/sic.2001.46.Supplement-1.47.

5. Stoner $J H$, Rushfield RA. The conservation of easel paintings. Abbingdon: Oxon, New York; 2012. p. 889.

6. Mecklenburg MF, Charola AE, Koestler RJ. New insights into the cleaning of paintings: proceedings from the cleaning 2010 international conference, Universidad Politécnica de Valencia and Museum Conservation Institute. Smithsonian Contributions to Museum Conservation, vol. 3, no. 3. 2013. p. 1-243. https://doi.org/10.5479/si.19492359.3.1.

7. Learner T. Modern paints uncovered, vol. 1. 2007. p. 317.

8. Casadio F, Keune K, Noble P, van Loon A, Hendriks E, Centeno S, Osmond G. Metal soaps in art. Cultural heritage science. Cham: Springer; 2019. https://doi.org/10.1007/978-3-319-90617-1.

9. Foster GM, Ritchie S, Lowe C. Controlled temperature and relative humidity dynamic mechanical analysis of paint films. J Therm Anal Calorim. 2003;73(1):119-26. https://doi.org/10.1023/A:1025133508109.

10. Ormsby B, Foster G, Learner T, Ritchie S, Schilling M. Improved controlled relative humidity dynamic mechanical analysis of artists'acrylic emulsion paints: part II. General properties and accelerated ageing. J Therm Anal Calorim. 2007;90(2):503-8. https://doi.org/10.1007/s1097 3-006-7725-9.

11. Hedley G, Odlyha M, Burnstock A, Tillinghast J, Husband C. A study of the mechanical and surface properties of oil paint films treated with organic solvents and water. Stud Conserv. 1990;35(sup1):98-105. https ://doi.org/10.1179/sic.1990.35.s1.022.

12. Fife GR, Stabik B, Kelley AE, King JN, Blümich B, Hoppenbrouwers R, Meldrum T. Characterization of aging and solvent treatments of painted surfaces using single-sided NMR. Magn Reson Chem. 2015;53(1):58-63. https://doi.org/10.1002/mrc.4164.

13. Baij L, Astefanei A, Hermans J, Brinkhuis F, Groenewegen H, Chassouant L, Johansson S, Corthals G, Tokarski C, ledema P, Keune K. Solvent-mediated extraction of fatty acids in bilayer oil paint models: a comparative analysis of solvent application methods. Herit Sci. 2019;7(1):31. https:// doi.org/10.1186/s40494-019-0273-y.

14. Michalski S. Paintings-their response to temperature, relative humidity, shock, and vibration. Art in transit: studies in the transport of paintings. 1991. p. 223-48.

15. Monico L, Van der Snickt G, Janssens K, De Nolf W, Miliani C, Verbeeck J, Tian H, Tan H, Dik J, Radepont M, Cotte M. Degradation process of lead chromate in paintings by Vincent van Gogh studied by means of synchrotron X-ray spectromicroscopy and related methods. 1. Artificially aged model samples. Anal Chem. 2011;83(4):1214-23. https://doi. org/10.1021/ac102424h.

16. Monico L, Van der Snickt G, Janssens K, De Nolf W, Miliani C, Dik J, Radepont M, Hendriks E, Geldof M, Cotte M. Degradation process of lead chromate in paintings by Vincent van Gogh studied by means of synchrotron X-ray spectromicroscopy and related methods. 2. Original paint layer samples. Anal Chem. 2011;83(4):1224-31. https://doi. org/10.1021/ac1025122.

17. Monico L, Janssens K, Miliani C, Van Der Snickt G, Brunetti BG, Cestelli Guidi M, Radepont M, Cotte M, Vagnini M, Vanmeert F, Falkenberg G, Abakumov A, Lu Y, Tian H, Verbeeck J, Radepont M, Cotte M, Hendriks E, Geldof M, Van Der Loeff L, Salvant J, Menu M. Degradation process of lead chromate in paintings by Vincent van Gogh studied by means of spectromicroscopic methods. 4. Artificial aging of model samples of Co-precipitates of lead chromate and lead sulfate. Anal Chem. 2013;85(2):860-7. https://doi.org/10.1021/ac302158b.

18. Monico L, Janssens K, Miliani C, Brunetti BG, Vagnini M, Vanmeert F, Falkenberg G, Abakumov A, Lu Y, Tian H, Verbeeck J, Radepont M, Cotte M, Hendriks E, Geldof M, Van Der Loeff L, Salvant J, Menu M. Degradation process of lead chromate in paintings by Vincent van Gogh studied by means of spectromicroscopic methods. 3. Synthesis, characterization, and detection of different crystal forms of the chrome yellow pigment. Anal Chem. 2013;85(2):851-9. https://doi.org/10.1021/ac302158b.

19. Kahrim K, Daveri A, Rocchi P, de Cesare G, Cartechini L, Miliani C, Brunetti BG, Sgamellotti A. The application of in situ mid-FTIR fibre-optic reflectance spectroscopy and GC-MS analysis to monitor and evaluate painting cleaning. Spectrochim Acta Part A Mol Biomol Spectrosc. 2009;74(5):1182-8. https://doi.org/10.1016/j.saa.2009.08.051.

20. Baglioni P, Baglioni M, Bonelli N, Chelazzi D, Giorgi R. Smart soft nanomaterials for cleaning. In: Nanotechnologies and nanomaterials for diagnostic, conservation and restoration of cultural heritage. Dordrecht: Elsevier; 2019. p. 171-204. https://doi.org/10.1016/B978-0-12-81391 0-3.00009-4

21. Angelova LV, Ormsby B, Townsend J, Wolbers R, editors. Gels in the conservation of art. London: Archetype Publications; 2018. p. 400.

22. Baij L, Hermans JJ, Keune K, ledema PD. Time-dependent ATR-FTIR spectroscopic studies on solvent diffusion and film swelling in oil paint model systems. Macromolecules. 2018;51(18):7134-44. https://doi. org/10.1021/acs.macromol.8b00890.

23. Genty-Vincent A, Eveno M, Nowik W, Bastian G, Ravaud E, Cabillic I, Uziel J, Lubin-Germain N, Menu M. Blanching of paint and varnish layers in easel paintings: contribution to the understanding of the alteration. Appl Phys A. 2015;121(3):779-88. https://doi.org/10.1007/s0033 9-015-9366-y.

24. Stolow N. Application of science to cleaning methods: solvent action studies on pigmented and unpigmented linseed oil films. Stud Conserv. 1961;6(sup1):84-8. https://doi.org/10.1179/sic.1961.s021.

25. Erhardt D, Tumosa CS Mecklenburg MF. Natural and accelerated thermal aging of oil paint films. In: Tradition and innovation: advances in conservation. Contributions to the IIC Melbourne Congress, 10-14 October 2000. 2000. p. 65-9.

26. Erhardt D, Tumosa CS, Mecklenburg MF. Can artists' oil paints be accelerated aged? Polym Preprints. 2000;41(2):1790-1.

27. Moutsatsou A, Alexopoulou A. A note on the construction of test panels for the spectral imaging of paintings. Stud Conserv. 2014;59(1):3-9. https://doi.org/10.1179/2047058413Y.0000000107.

28. Lazzari M, Chiantore O. Drying and oxidative degradation of linseed oil. Polym Degrad Stab. 1999;65(2):303-13. https://doi.org/10.1016/S0141 -3910(99)00020-8.

29. van Gorkum R, Bouwman E. The oxidative drying of alkyd paint catalysed by metal complexes. Coord Chem Rev. 2005;249(17-18):1709-28. https://doi.org/10.1016/j.ccr.2005.02.002.

30. Soucek MD, Khattab T, Wu J. Review of autoxidation and driers. Prog Org Coat. 2012;73(4):435-54. https://doi.org/10.1016/j.porgc oat.2011.08.021.

31. Tan $H$, Tian $H$, Verbeeck J, Monico L, Janssens $K$, Van Tendeloo $G$. Nanoscale investigation of the degradation mechanism of a historical chrome yellow paint by quantitative electron energy loss spectroscopy mapping of chromium species. Angew Chem Int Ed. 2013;52(43):11360-3. https://doi.org/10.1002/anie.201305753.

32. Baij L, Chassouant L, Hermans JJ, Keune K, ledema PD. The concentration and origins of carboxylic acid groups in oil paint. RSC Adv. 2019;9(61):35559-64. https://doi.org/10.1039/C9RA06776K.

33. Mills J, White R. Organic chemistry of museum objects. Oxford: Routledge; 2012. https://doi.org/10.4324/9780080513355.

34. De la Rie ER. Old master paintings: a study of the varnish problem. Anal Chem. 1989;61(21):1228-40. https://doi.org/10.1021/ac00196a003.

35. Sutherland K. The extraction of soluble components from an oil paint film by a varnish solution. Stud Conserv. 2000;45(1):54. https://doi. org/10.2307/1506683.

36. Poli T, Piccirillo A, Zoccali A, Conti C, Nervo M, Chiantore O. The role of zinc white pigment on the degradation of shellac resin in artworks. 
Polym Degrad Stab. 2014;102(1):138-44. https://doi.org/10.1016/j. polymdegradstab.2014.01.026.

37. Keune K, Mass J, Mehta A, Church J, Meirer F. Analytical imaging studies of the migration of degraded orpiment, realgar, and emerald green pigments in historic paintings and related conservation issues. Herit Sci. 2016;4(1):10. https://doi.org/10.1186/s40494-016-0078-1.

38. Wolbers R. Cleaning painted surfaces: aqueous methods. London: Archetype Publications; 2000. p. 198.

39. Ormsby BA, Soldano A, Keefe MH, Phenix A, Learner T. An empirical evaluation of a range of cleaning agents for removing dirt from artists ' acrylic emulsion paints. AIC Paint Spec Gr Postprints. 2010;23:1-11.

40. Hermans JJ, Keune K, van Loon A, Corkery RW, ledema PD. lonomer-like structure in mature oil paint binding media. RSC Adv. 2016;6(96):933639. https://doi.org/10.1039/C6RA18267D.

41. Hermans JJ, Baij L, Koenis M, Keune K, ledema PD, Woutersen S. 2D-IR spectroscopy for oil paint conservation: elucidating the watersensitive structure of zinc carboxylate clusters in ionomers. Sci Adv. 2019:5(6):3592. https://doi.org/10.1126/sciadv.aaw3592.

42. Tant MR, Mauritz KA, Wilkes GL. lonomers: synthesis, structure, properties and applications. Dordrecht: Springer; 1997. p. 528.

43. Kerres JA. Blended and cross-linked ionomer membranes for application in membrane fuel cells. Fuel Cells. 2005;5(2):230-47. https://doi. org/10.1002/fuce.200400079.

44. Shahinpoor M, Bar-Cohen Y, Simpson JO, Smith J. Ionic polymer-metal composites (IPMCs) as biomimetic sensors, actuators and artificial muscles_a review. Smart Mater Struct. 1998;7(6):15-30. https://doi. org/10.1088/0964-1726/7/6/001.

45. Hatipoglu G, Liu Y, Zhao R, Yoonessi M, Tigelaar DM, Tadigadapa S, Zhang QM. A highly aromatic and sulfonated ionomer for high elastic modulus ionic polymer membrane micro-actuators. Smart Mater Struct. 2012;21(5):055015. https://doi.org/10.1088/0964-1726/21/5/055015.

46. Li J, Park JK, Moore RB, Madsen LA. Linear coupling of alignment with transport in a polymer electrolyte membrane. Nat Mater. 2011;10(7):507-11. https://doi.org/10.1038/nmat3048.

47. Oh KT, Bronich TK, Bromberg L, Hatton TA, Kabanov AV. Block ionomer complexes as prospective nanocontainers for drug delivery. I Control Release. 2006;115(1):9-17. https://doi.org/10.1016/j.jconrel.2006.06.030.

48. van der Wel GK, Adan OCG. Moisture in organic coatings-a review. Prog Org Coat. 1999;37(1-2):1-14. https://doi.org/10.1016/50300 -9440(99)00058-2.

49. Xu Y, Yan C, Ding J, Gao Y, Cao C. Water vapour in the coatings of alkyd and polyurethane varnish. Prog Org Coat. 2002;45(4):331-9. https://doi. org/10.1016/S0300-9440(02)00069-3.

50. van der Zanden AJJ, Goossens ELJ. The measurement of the diffusion coefficient and the sorption isotherm of water in paint films. Chem Eng Sci. 2003;58(8):1521-30. https://doi.org/10.1016/S0009-2509(02)00674 $-7$.

51. Hallinan DT Jr, Elabd YA, Hallinan DT, Elabd YA. Diffusion and sorption of methanol and water in nafion using time-resolved fourier transform infrared-attenuated total reflectance spectroscopy. J Phys Chem B. 2007;111(46):13221-30. https://doi.org/10.1021/jp811325v.

52. Modesti G, Zimmermann B, Borsch M, Herrmann A, Saalwachter K. Diffusion in model networks as studied by NMR and fluorescence correlation spectroscopy. Macromolecules. 2009;42(13):4681-9. https://doi. org/10.1021/ma900614j.

53. Philippe L, Sammon C, Lyon SB, Yarwood J. An FTIR/ATR in situ study of sorption and transport in corrosion protective organic coatings. Prog Org Coat. 2004;49(4):302-14. https://doi.org/10.1016/j.porgc oat.2003.07.002.

54. Ward SA, Pethrick RA. Positron annihilation lifetime spectroscopy and diffusion studies of large molecule penetrants into alkyd resins. Prog Org Coat. 2012;75(4):509-26. https://doi.org/10.1016/j.porgc oat.2012.06.002.

55. Van Alsten JG, Lustig SR. Polymer mutual diffusion measurements using infrared ATR spectroscopy. Macromolecules. 1992;25(19):5069-73. https ://doi.org/10.1021/ma00045a037.

56. Farinas KC, Doh L, Venkatraman S, Potts RO. Characterization of solute diffusion in a polymer using ATR-FTIR spectroscopy and bulk transport techniques. Macromolecules. 1994;27(18):5220-2.

57. Van Alsten JG. Ionic and chain interdiffusion and interfacial strength development in ionomers of poly(ethylene-co-methacrylic acid).
Macromolecules. 1996;29(6):2163-8. https://doi.org/10.1021/ma950 $431 f$.

58. Dias M, Hadgraft J, Raghavan SL, Tetteh J. The effect of solvent on permeant diffusion through membranes studied using ATR-FTIR and chemometric data analysis. J Pharm Sci. 2004;93(1):186-96. https://doi. org/10.1002/jps.10530.

59. Fleming OS, Chan KLA, Kazarian SG. High-pressure $\mathrm{CO}_{2}$-enhanced polymer interdiffusion and dissolution studied with in situ ATR-FTIR spectroscopic imaging. Polymer. 2006;47(13):4649-58. https://doi. org/10.1016/j.polymer.2006.04.059.

60. Hong SU, Barbari TA, Sloan JM. Multicomponent diffusion of methyl ethyl ketone and toluene in polyisobutylene from vapor sorption FTIRATR spectroscopy. J Polym Sci Part B Polym Phys. 1998;36(2):337-44.

61. Sammon C, Yarwood J, Everall N. A FTIR-ATR study of liquid diffusion processes in PET films: comparison of water with simple alcohols. Polymer. 2000;41(7):2521-34. https://doi.org/10.1016/S0032-3861(99)00405 $-X$.

62. Guo J, Barbari TA. Unified dual mode description of small molecule sorption and desorption kinetics in a glassy polymer. Macromolecules. 2009:42(15):5700-8. https://doi.org/10.1021/ma9007576.

63. Jackson DA, Koberstein JT, Weiss RA. Small-angle X-ray scattering studies of zinc stearate-filled sulfonated poly(ethylene-co-propyleneco-ethylidene norbornene) ionomers. J Polym Sci Part B Polym Phys. 1999;37(21):3141-50. https://doi.org/10.1002/(SICI)1099-0488(19991 101)37:21<3141::AID-POLB23>3.0.CO;2-I.

64. Wakabayashi K, Register RA. Ethylene/(meth)acrylic acid ionomers plasticized and reinforced by metal soaps. Polymer. 2006;47(8):2874-83. https://doi.org/10.1016/j.polymer.2006.02.019.

65. Ikeda Y, Yasuda Y, Ohashi T, Yokohama H, Minoda S, Kobayashi H Honma T. Dinuclear bridging bidentate zinc/stearate complex in sulfur cross-linking of rubber. Macromolecules. 2015:48(3):462-75. https://doi. org/10.1021/ma502063m.

66. Barberio M, Skantzakis E, Sorieul S, Antici P. Pigment darkening as case study of in-air plasma-induced luminescence. Sci Adv. 2019;5(6):6228. https://doi.org/10.1126/sciadv.aar6228.

67. Seniha Güner, F, Yağc Y, Tuncer Erciyes A. Polymers from triglyceride oils. Prog Polym Sci. 2006;31(7):633-70. https://doi.org/10.1016/j.progp olymsci.2006.07.001.

68. Hofland A. Alkyd resins: from down and out to alive and kicking. Prog Org Coat. 2012;73(4):274-82. https://doi.org/10.1016/j.porgc oat.2011.01.014.

69. Baij L, Hermans JJ, Keune K, ledema P. Time-dependent ATR-FTIR spectroscopic studies on fatty acid diffusion and the formation of metal soaps in oil paint model systems. Angew Chem Int Ed. 2018;57(25):7351-4. https://doi.org/10.1002/anie.201712751.

70. Chung JY, Ormsby B, Lee J, Burnstock A, van den Berg KJ. An investigation of options for surface cleaning unvarnished water-sensitive oil paints based on recent developments for acrylic paints. ICOM-CC 18th Triennial Conference Preprints, Copenhagen, 4-8 September 2017. 2017.

71. Silvester G, Burnstock A, Megens L, Learner T, Chiari G, van den Berg KJ. A cause of water-sensitivity in modern oil paint films: the formation of magnesium sulphate. Stud Conserv. 2014;59(1):38-51. https://doi. org/10.1179/2047058413Y.0000000085.

72. Banti D, La Nasa J, Tenorio AL, Modugno F, van den Berg KJ, Lee J, Ormsby B, Burnstock A, Bonaduce I. A molecular study of modern oil paintings: investigating the role of dicarboxylic acids in the water sensitivity of modern oil paints. RSC Adv. 2018;8(11):6001-12. https:// doi.org/10.1039/C7RA13364B.

73. Lee J, Bonaduce I, Modugno F, La Nasa J, Ormsby B, van den Berg KJ. Scientific investigation into the water sensitivity of twentieth century oil paints. Microchem J. 2018;138:282-95. https://doi.org/10.1016/j. microc.2018.01.017.

74. La Nasa J, Lee J, Degano I, Burnstock A, van den Berg KJ, Ormsby B, Bonaduce I. The role of the polymeric network in the water sensitivity of modern oil paints. Sci Rep. 2019;9(1):3467. https://doi.org/10.1038/ s41598-019-39963-z.

75. Perera DY. Effect of pigmentation on organic coating characteristics. Prog Org Coat. 2004;50(4):247-62. https://doi.org/10.1016/j.porgc oat.2004.03.002. 
76. Erich SJF, Huinink HP, Adan OCG, Laven J, Esteves AC. The influence of the pigment volume concentration on the curing of alkyd coatings: a 1D MRI depth profiling study. Prog Org Coat. 2008;63(4):399-404. https ://doi.org/10.1016/j.porgcoat.2008.06.007.

77. Bay L, Burnstock A, Lee J, Ormsby B, van den Berg KJ. Water sensitivity of modern oil paintings. ICOM-CC 18th triennial conference preprints, Copenhagen, 4-8 September 2017, 1302. 2017;

78. Morsch S, Van Driel BA, Van Den Berg KJ, Dik J. Investigating the photocatalytic degradation of oil paint using ATR-IR and AFM-IR. ACS App Mater Interfaces. 2017;9(11):10169-79. https://doi.org/10.1021/acsam i.7b00638.

79. Burnstock A, van den Berg KJ, de Groot S, Wijnberg L. An investigation of water-sensitive oil paints in twentieth-century paintings. Modern paints uncovered. 2007. p. 177-88.

80. Blumenroth D, Zumbühl S, Scherrer NC, Müller W. Sensitivity of modern oil paints to solvents. Effects on synthetic organic pigments. In: Issues in contemporary oil paint. Cham: Springer; 2014. p. 351-62.

81. Fuesers $\mathrm{O}$, Zumbühl $\mathrm{S}$. The influence of organic solvents on the mechanical properties of alkyd and oil paint. In: 9th international conference on NDT of Art, Jerusalem, Israel, 25-30 May 2008 (May). 2008. p. $1-14$

82. Dossie R. The handmaid to the arts, London. 1764

83. Manfred K. Surface cleaning and conservation. https://www.getty.edu/ conservation/publications resources/newsletters/15 3/feature.html. Accessed 13 Dec 2019.

84. Church $\mathrm{AH}$. The chemistry of paints and paintings. 4th ed. Seeley: Service \& Co., Limited, London; 1915

85. De Wild A.M. Het natuurwetenschappelijk onderzoek van schilderijen. PhD thesis, Technische Universiteit Delft 1928.

86. Stolow N. A modified apparatus for measuring the swelling of polymer films in solvents. J Sci Instrum. 1954;31(11):416-20. https://doi. org/10.1088/0950-7671/31/11/309.

87. Stolow N. The action of solvents on drying-oil films: parts I and II. J Oil Colour Chem Assoc. 1957;40(5-6):377-402.

88. Stolow N. Action of solvents on dried linseed oil films. Nature. 1957;179(4559):579-80. https://doi.org/10.1038/179579b0.

89. Ruhemann H, Plesters J. The cleaning of paintings; problems and potentialities. London: Faber; 1968. p. 508.

90. Modestini DD. John Brealey and the cleaning of paintings. Metrop Mus J. 2005;40:27-36. https://doi.org/10.1484/J.MMJ.2.301725.

91. Brouwer T, Schuur B. Model performances evaluated for infinite dilution activity coefficients prediction at 298.15 K. Ind Eng Chem Res. 2019. https://doi.org/10.1021/acs.iecr.9b00727

92. Baglioni P, Chelazzi D, editors. Nanoscience for the conservation of works of art. Nanoscience \& nanotechnology series. Cambridge: Royal Society of Chemistry; 2013. https://doi.org/10.1039/9781849737630. http://ebook.rsc.org/?DOl=10.1039/9781849737630

93. Hildebrand JH, Scott RL. The solubility of nonelectrolytes, 3rd edn. American Chemical Society monograph series. New York: Dover Publications, Inc.; 1964. https://archive.org/details/solubilityofnone00hild/ page/n7

94. Teas JP. Graphic analysis of resin solubilities. J Paint Technol. 1968:40(516):19-25.

95. Fink JK. Terpene resins. In: Reactive polymers fundamentals and applications. Leoben: Elsevier; 2013. p. 303-15. https://doi.org/10.1016/B978-14557-3149-7.00012-7

96. Hansen CM. The three dimensional solubility parameter. PhD thesis. 1967.

97. Hansen CM. Hansen solubility parameters. London: CRC Press; 2007. https://doi.org/10.1201/9781420006834. https://www.taylorfrancis. com/books/9781420006834

98. Hedley G. Solubility parameters and varnish removal a survey. Conservator. 1980;4(1):12-8. https://doi.org/10.1080/01410096.1980.9994931.

99. Chelazzi D, Giorgi R, Baglioni P. Microemulsions, micelles, and functional gels: how colloids and soft matter preserve works of art. Angew Chem Int Ed. 2018. https://doi.org/10.1002/anie.201710711.

100. Phenix A, Mar Parkin H. The swelling of artists' paints by organic solvents and the cleaning of paintings: recent perspectives, future directions. In: 2002 AIC paintings specialty group postprints, Miami, Florida, June 6-11, 2002. 2002. p. 71-86
101. Barton AFM. CRC handbook of solubility parameters and other cohesion parameters, 2nd edn. New York: Routledge; 1991. https://doi. org/10.1201/9781315140575. https://www.taylorfrancis.com/books 19781351457194

102. Kanegsberg B, Kanegsberg E. Handbook for critical cleaning. Abingdon: CRC Press; 2011. https://doi.org/10.1201/b10897.

103. Stavroudis C, Blank S. Solvents \& sensibility. WAAC Newsl. 1989;11(2):2-10.

104. Phenix A. Effects of organic solvents on artists' oil paint films: swelling. Smithsonian contributions to museum conservation 3(November 2013), 2013. p. 69-76.

105. Phenix A, Graczyk A. Mapping the nonideal: reflections on graphical representation of solubility parameters as a tool in conservation practice. AIC Paint Spec Group Postprints. 2015;28:89-97.

106. Phenix A. Solubility parameters and the cleaning of paintings: an update and review. Zeitschrift für Kunsttechnologie und Konservierung. 1998;12(2):387-409.

107. Zumbuhl S, Scherrer NC, Engel NL, Muller W. The kinetics of dissolution of varnishes: the influence of vapour pressure on the rate of solvent action. In: ICOM-CC, 17th triennial conference. 2014. p. 1-11.

108. Zumbühl S. Illusion mit System: das Lösemitteldreieck in der Praxis: Aspekte zur Charakterisierung der Wirkung von binären Lösemittelmischungen. Zeitschrift für Kunsttechnologie und Konservierung: ZKK. 2005:19(2):253-63.

109. Zumbühl S. Parametrization of the solvent action on modern artists' paint systems. Stud Conserv. 2014;59(1):24-37. https://doi. org/10.1179/2047058413Y.0000000099.

110. Phenix A. The swelling of artists' paints in organic solvents. Part 2, comparative swelling powers of selected organic solvents and solvent mixtures. J Am Inst Conserv. 2002;41(1):61. https://doi. org/10.2307/3179897.

111. Zumbühl S. Solvents, solvation, solubilization, solution: the solubility of materials-an introduction for conservators including solubility data of selected conservation materials. Bern: HDW Publications; 2019.

112. Saera Vila A, Barros Garcia JM. Extended abstract computer applications and cleaning: teas fractional solubility parameter system in conservation. In: New insights into the cleaning of paintings: proceedings from the cleaning 2010 international conference Universidad Politecnica de Valencia and Museum Conservation Institute. 2013. p. 35-8.

113. Macchia A, Rivaroli L, Gianfreda B. The GREEN RESCUE: a 'green' experimentation to clean old varnishes on oil paintings. Nat Prod Res. 2019;1-11: https://doi.org/10.1080/14786419.2019.1675061.

114. Stavroudis C, Doherty T. A novel approach to cleaning II: extending the Modular Cleaning Program to solvent gels and free solvents, part 1. Newsletter. 2007;29(3):9-15.

115. Fardi T, Stefanis E, Panayiotou C, Abbott S, van Loon S. Artwork conservation materials and Hansen solubility parameters: a novel methodology towards critical solvent selection. J Cult Herit. 2014;15(6):583-94. https://doi.org/10.1016/j.culher.2013.11.006

116. Horta A, Pastoriza MA. The interaction parameter of crosslinked networks and star polymers. 2005. https://doi.org/10.1016/j.eurpo lymj.2005.06.020.

117. Quesada-Pérez M, Maroto-Centeno JA, Forcada J, Hidalgo-Alvarez R. Gel swelling theories: the classical formalism and recent approaches. 2011. https://doi.org/10.1039/c1sm06031g.

118. Lopez CG, Richtering W. Does Flory-Rehner theory quantitatively describe the swelling of thermoresponsive microgels? Soft Matter. 2017;13(44):8271-80. https://doi.org/10.1039/c7sm01274h.

119. Browne FL. The absorption of water, swelling and solubility of free films of paint. For Prod J. 1953;3:108-25.

120. Browne FL. Swelling of paint films in water III absorption and volumetric swelling of bound and free films from air of different relative humidities. For Prod J. 1955;5:92-6.

121. Browne FL. Swelling of pain films in water IV effects of thickness of film and pigment volume of paint. For Prod J. 1955;5:142-6.

122. Browne FL. Swelling of paint films in water $V$ effects of different pigments. For Prod J. 1955;5:192-200.

123. Browne FL. Swelling of paint films in water VI effects of different oil or oleoresinous vehicles. For Prod J. 1956:6:152-9. 
124. Browne FL. Swelling of paint films in water VII latex vehicles. For Prod J. 1956;6:235-40.

125. Browne FL. Swelling of paint films in water VIII: swelling of linseed oil paints in water and organic liquids. For Prod J. 1956;6:312-8.

126. Browne FL. Swelling of paint films in water IX effects of temperature during soaking and film formation, and repeated soaking and drying. For Prod J. 1956;6:453-8.

127. Browne FL. Swelling of paint films in water $X$ rate of penetration of water, and pentrability to air in relation to water absorption. For Prod J. 1957;7:145-54.

128. Browne FL. Swelling of paint films in water, XI: mixed-pigment paints in linseed oil. For Prod J. 1957;7(7):248-52.

129. Phenix A. The swelling of artists' paints in organic solvents. Part 1, a simple method for measuring the in-plane swelling of unsupported paint films. J Am Inst Conserv. 2002;41(1):43. https://doi.org/10.2307/31798 96.

130. Liu B, Li Y, Lin H, Cao C-n. Effect of PVC on the diffusion behaviour of water through alkyd coatings. Corros Sci. 2002;44(12):2657-64. https:// doi.org/10.1016/S0010-938X(02)00061-6.

131. Erhardt D, Tsang J-S. The extractable components of oil paint films. Stud Conserv. 1990;35(sup1):93-7. https://doi.org/10.1179/sic.1990.35.s1.021.

132. White R, Roy A. GC-MS and SEM studies on the effects of solvent cleaning on old master paintings from the National Gallery, London. Stud Conserv. 1998;43(3):159-76. https://doi.org/10.1179/sic.1998.43.3.159.

133. van den Berg JDJ, van den Berg KJ, Boon JJ. Identification of non-crosslinked compounds in methanolic extracts of cured and aged linseed oil-based paint films using gas chromatography-mass spectrometry. J Chromatogr A. 2002;950(1):195-211. https://doi.org/10.1016/S0021 -9673(02)00049-3.

134. Sutherland K. Solvent-extractable components of linseed oil paint films. Stud Conserv. 2003;48(2):111-35.

135. Sutherland K. Measurements of solvent cleaning effects on oil paintings. J Am Inst Conserv. 2006;45(3):211-26. https://doi. org/10.1179/019713606806112487.

136. Spyros A, Anglos D. Study of aging in oil paintings by $1 D$ and $2 D$ NMR spectroscopy. Anal Chem. 2004;76(17):4929-36. https://doi. org/10.1021/ac049350k

137. Spyros A, Anglos D. Studies of organic paint binders by NMR spectroscopy. Appl Phys A Mater Sci Process. 2006;83(4):705-8. https://doi. org/10.1007/s00339-006-3532-1.

138. Casoli A, Di Diego Z, Isca C. Cleaning painted surfaces: evaluation of leaching phenomenon induced by solvents applied for the removal of gel residues. Environ Sci Pollut Res. 2014;21(23):13252-63. https://doi. org/10.1007/s11356-014-2658-5.

139. Burnstock $A$, Learner T. Changes in the surface characteristics of artificially aged mastic varnishes after cleaning using alkaline reagents. Stud Conserv. 1992;37(3):165. https://doi.org/10.2307/1506344.

140. McGlinchey CW. Thermal analysis of fresh and mature oil paint films: the effect of pigments as driers and the solvent leaching of mature paint films. MRS Proc. 1990;185:93. https://doi.org/10.1557/ PROC-185-93.

141. Mecklenburg MF, Tumosa CS, Erhardt D. The changing mechanical properties of aging oil paints. MRS Proc. 2004;852(852):1-3. https://doi. org/10.1557/PROC-852-003.1.

142. Erhardt D, Tumosa CS, Mecklenburg MF. Long-term chemical and physical processes in oil paint films. Stud Conserv. 2005;50(2):143-50. https:// doi.org/10.2307/25487732.

143. Prati S, Sciutto G, Volpi F, Rehorn C, Vurro R, Blümich B, Mazzocchetti L, Giorgini L, Samorì C, Galletti P, Tagliavini E, Mazzeo R. Cleaning oil paintings: NMR relaxometry and SPME to evaluate the effects of green solvents and innovative green gels. New J Chem. 2019;43(21):8229-38. https://doi.org/10.1039/C9NJ00186G.

144. Ordonez E, Twilley J. Peer reviewed: clarifying the haze: efflorescence on works of art. Anal Chem. 1997;69(13):416-22. https://doi.org/10.1021/ ac971692l.

145. Blümich B, Blümler P, Eidmann G, Guthausen A, Haken R, Schmitz U, Saito K, Zimmer G. The NMR-MOUSE: construction, excitation, and applications. Magn Reson Imaging. 1998;16(5-6):479-84. https://doi. org/10.1016/S0730-725X(98)00069-1.
146. Feller RL, Stolow N, Jones EH. On picture varnishes and their solvents. Cleveland and London: The Press of Case Western Reserve University; 1985.

147. Van Den Berg JDJ, Van Den Berg KJ, Boon JJ. Determination of the degree of hydrolysis of oil paint samples using a two-step derivatisation method and on-column GC/MS. Prog Org Coat. 2001;41(1-3):143-55. https://doi.org/10.1016/S0300-9440(01)00140-0.

148. Sutherland K. Derivatisation using m-(trifluoromethyl)phenyltrimethylammonium hydroxide of organic materials in artworks for analysis by gas chromatography-mass spectrometry: Unusual reaction products with alcohols. J Chromatogr A. 2007;1149(1):30-7. https://doi. org/10.1016/j.chroma.2006.12.015.

149. Modugno F, Gianvincenzo FD, Degano I, Van Der Werf I, Bonaduce I, Van Den Berg J, Di Gianvincenzo F, Degano I, van der Werf ID, Bonaduce I, van den Berg KJ. On the influence of relative humidity on the oxidation and hydrolysis of fresh and aged oil paints. Sci Rep. 2019;9(1):5533. https://doi.org/10.1038/s41598-019-41893-9.

150. Schilling MR, Heginbotham A, van Keulen H, Szelewski M. Beyond the basics: a systematic approach for comprehensive analysis of organic materials in Asian lacquers. Stud Conserv. 2016;61(sup3):3-27. https:// doi.org/10.1080/00393630.2016.1230978.

151. Bonaduce I, Carlyle L, Colombini MP, Duce C, Ferrari C, Ribechini E, Selleri P, Tiné MR. New insights into the ageing of linseed oil paint binder: a qualitative and quantitative analytical study. PLOS ONE. 2012;7(11):49333. https://doi.org/10.1371/journal.pone.0049333.

152. van Dam EP, van den Berg KJ, Proaño Gaibor AN, van Bommel M. Analysis of triglyceride degradation products in drying oils and oil paints using LC-ESI-MS. Int J Mass Spectrom. 2017;413:33-42. https:// doi.org/10.1016/j.ijms.2016.09.004.

153. La Nasa J, Modugno F, Aloisi M, Lluveras-Tenorio A, Bonaduce I. Development of a GC/MS method for the qualitative and quantitative analysis of mixtures of free fatty acids and metal soaps in paint samples. Anal Chim Acta. 2018;1001:51-8. https://doi.org/10.1016/j.aca.2017.11.017.

154. Masschelein-Kleiner L. Les Solvants. Bruxelles: Cours de conservation. Institut royal du patrimoine artistique; 1994.

155. Prati S, Volpi F, Fontana R, Galletti P, Giorgini L, Mazzeo R, Mazzocchett L, Samorì C, Sciutto G, Tagliavini E. Sustainability in art conservation: a novel bio-based organogel for the cleaning of water sensitive works of art. Pure Appl Chem. 2018;90(2):239-51. https://doi.org/10.1515/ pac-2017-0507.

156. Baij L, Buijs J, Hermans JJ, Raven L, ledema PD, Keune K, Sprakel J. Quantifying solvent action in oil paint using portable laser speckle imaging. 2020. (Submitted).

157. Hermans JJ, Keune K, van Loon A, ledema PD. The crystallization of metal soaps and fatty acids in oil paint model systems. Phys Chem Chem Phys. 2016;18(16):10896-905. https://doi.org/10.1039/C6CP0 0487C.

158. Tauber G, Smelt S, Noble P, Kirsch K, Siejek A, Keune K, van Keulen H, Smulders-De Jong S, Erdman R, Evolon CR. Its use from a scientific and practical conservation perspective. AIC Painti Spec Group Postprints. 2018:31:45-50.

159. Ankersmit B, Stappers MHL. Managing indoor climate risks in museums. Cult Herit Sci. 2017; https://doi.org/10.1007/978-3-319-34241-2.

160. Stulik D, Miller D, Khanjian H, Khandekar N, Wolbers R, Carlson J, Peterson WC. Solvent gels for the cleaning of works of art: the residue question. Los Angeles: The Getty Conservation Institute; 2004.

161. Domingues JAL, Bonelli N, Giorgi R, Fratini E, Gorel F, Baglioni P. Innovative hydrogels based on semi-interpenetrating p(HEMA)/PVP networks for the cleaning of water-sensitive cultural heritage artifacts. Langmuir. 2013;29(8):2746-55. https://doi.org/10.1021/la3048664.

162. Samorì C, Galletti P, Giorgini L, Mazzeo R, Mazzocchetti L, Prati S, Sciutto G, Volpi F, Tagliavini E. The green attitude in art conservation: polyhydroxybutyrate-based gels for the cleaning of oil paintings. ChemistrySelect. 2016;1(15):4502-8. https://doi.org/10.1002/slct.20160 1180

163. Angelova LV, Ormsby B, Richardson E. Diffusion of water from a range of conservation treatment gels into paint films studied by unilateral NMR. Microchem J. 2016;124:311-20. https://doi.org/10.1016/j.micro c.2015.09.012. 
164. Volpi F. Green strategies for the cleaning of works of art setting up of an analytical protocol for the evaluation of cleaning. PhD thesis, alma 2017. https://doi.org/10.6092/unibo/amsdottorato/8050

165. Bartoletti A, Barker R, Chelazzi D, Bonelli N, Baglioni P, Lee J, Angelova LV, Ormsby B. Reviving WHAAM! a comparative evaluation of cleaning systems for the conservation treatment of Roy Lichtenstein's iconic painting. Herit Sci. 2020;8(1):9. https://doi.org/10.1186/s40494-020-0350-2.

166. Nič M, Jirát J, Košata $B$, Jenkins A, McNaught A, editors. IUPAC compendium of chemical terminology. Research Triangle Park: IUPAC; 2009. https://doi.org/10.1351/goldbook. http://goldbook.iupac.org. Accessed 31 Mar 2020.

167. Baglioni P, Chelazzi D, Giorgi R. Nanotechnologies in the conservation of cultural heritage: a compendium of materials and techniques. Dordrecht: Springer; 2014. p. 144. https://doi.org/10.1007/978-94-017 9303-2. http://www.worldcat.org/oclc/896824873. Accessed 31 Mar 2020

168. Baglioni P, Carretti E, Chelazzi D. Nanomaterials in art conservation. Nat Nanotechnol. 2015;10(4):287-90. https://doi.org/10.1038/nnano .2015.38.

169. Domingues J, Bonelli N, Giorgi R, Fratini E, Baglioni P. Innovative method for the cleaning of water- sensitive artifacts: synthesis and application of highly retentive chemical hydrogels. Int J Conserv Sci. 2013;4:715-22.

170. Angelova LV, Terech P, Natali I, Dei L, Carretti E, Weiss RG. Cosolvent gellike materials from partially hydrolyzed poly(vinyl acetate)s and borax. Langmuir. 2011;27(18):11671-82. https://doi.org/10.1021/la202179e.

171. Angelova LV, Berrie BH, de Ghetaldi K, Kerr A, Weiss RG. Partially hydrolyzed poly(vinyl acetate)-borax-based gel-like materials for conservation of art: characterization and applications. Stud Conserv. 2015;60(4):22744. https://doi.org/10.1179/2047058413Y.0000000112.

172. Duncan TT, Berrie BH, Weiss RG. Soft, peelable organogels from partially hydrolyzed poly(vinyl acetate) and benzene-1,4-diboronic acid: applications to clean works of art. ACS Appl Mater Interfaces. 2017:9(33):28069-78. https://doi.org/10.1021/acsami.7b09473.

173. Duncan TT, Weiss RG. Influence of length and structure of aryl boronic acid crosslinkers on organogels with partially hydrolyzed poly(vinyl acetate). Colloid Polym Sci. 2018;296(6):1047-56. https://doi.org/10.1007/ s00396-018-4326-7.

174. Morris ER, Nishinari K, Rinaudo M. Gelation of gellan-a review. Food Hydrocoll. 2012;28(2):373-411. https://doi.org/10.1016/j.foodh yd.2012.01.004.

175. Lahaye M, Rochas C. Chemical structure and physico-chemical properties of agar. Hydrobiologia. 1991;221(1):137-48. https://doi.org/10.1007/ BF00028370.

176. van den Berg KJ, Burnstock A, de Keijzer M, Krueger J, Learner T, de Tagle A, Heydenreich G, editors. Issues in contemporary oil paint. Cham: Springer; 2014. https://doi.org/10.1007/978-3-319-10100-2.

177. Davies E, Huang Y, Harper JB, Hook JM, Thomas DS, Burgar IM, Lillford PJ. Dynamics of water in agar gels studied using low and high resolution
1H NMR spectroscopy. Int J Food Sci Technol. 2010;45(12):2502-7. https ://doi.org/10.1111/j.1365-2621.2010.02448.x.

178. Scott $\mathrm{CL}$. The use of agar as a solvent gel in objects conservation. Objects Spec Group Postprints. 2012;19:71-83.

179. Ormsby B, Keefe M, Phenix A, von Aderkas E, Learner T, Tucker C, Kozak C. Mineral spirits-based microemulsions: a novel cleaning system for painted surfaces. J Am Inst Conserv. 2016;55(1):12-31. https://doi. org/10.1080/01971360.2015.1120406.

180. Cremonesi P. Surface cleaning? Yes, freshly grated Agar gel, please. Stud Conserv. 2016;61(6):362-7. https://doi.org/10.1179/2047058415Y.00000 00026.

181. Wolbers RC. A radio-isotopic assay for the direct measurement of residual cleaning materials on a paint film. Stud Conserv. 1990;35(sup1):11925. https://doi.org/10.1179/sic.1990.35.s1.025.

182. Fife G, Och JV, Stabik B, Miedema N, Seymour K. A package deal: the development of tissue gel composite cleaning at SRAL. In: ICOM-CC 16th triennial conference Lisbon 19-23 September 2011: preprints. 2011.

183. Pizzorusso G, Fratini E, Eiblmeier J, Giorgi R, Chelazzi D, Chevalier A, Baglioni P. Physicochemical characterization of acrylamide/bisacrylamide hydrogels and their application for the conservation of easel paintings. Langmuir. 2012;28(8):3952-61. https://doi.org/10.1021/la204 4619.

184. Domingues J, Bonelli N, Giorgi R, Baglioni P. Chemical semi-IPN hydrogels for the removal of adhesives from canvas paintings. Appl Phys $A$. 2014;114(3):705-10. https://doi.org/10.1007/s00339-013-8150-0.

185. Noferini D, Faraone A, Rossi M, Mamontov E, Fratini E, Baglioni P. Disentangling polymer network and hydration water dynamics in polyhydroxyethyl methacrylate physical and chemical hydrogels. J Phys Chem C. 2019;123(31):19183-94. https://doi.org/10.1021/acs.jpcc.9b04212.

186. Moretti P, Cartechini L, Miliani C. Single-sided NMR: a non-invasive diagnostic tool for monitoring swelling effects in paint films subjected to solvent cleaning. Anal Bioanal Chem. 2019;412(5):1063-75. https:// doi.org/10.1007/s00216-019-02331-x.

187. Baij L, Keune K, Hermans JJ, Noble P, ledema PD. Time-resolved ATR-FTIR studies on the release of solvents from cleaning gels into model systems of oil paint binding media. In: Ormsby B, Townsend JH, Wolbers R, editors. Gels in the conservation of art. London: Archetype Publications; 2017. p. 316-21.

188. Hermans JJ, Keune K, van Loon A, ledema PD. An infrared spectroscopic study of the nature of zinc carboxylates in oil paintings. J Anal At Spectrom. 2015;30(7):1600-8. https://doi.org/10.1039/C5JA00120J.

\section{Publisher's Note}

Springer Nature remains neutral with regard to jurisdictional claims in published maps and institutional affiliations.

\section{Submit your manuscript to a SpringerOpen ${ }^{\circ}$ journal and benefit from:}

- Convenient online submission

- Rigorous peer review

- Open access: articles freely available online

- High visibility within the field

- Retaining the copyright to your article

Submit your next manuscript at $\boldsymbol{\nabla}$ springeropen.com 